\title{
Avaliação do metabolismo ósseo e composição corporal em pacientes com dermatomiosite juvenil
}

Tese apresentada à Faculdade de Medicina da Universidade de São Paulo, para obtenção do título de Doutor em Ciências

Área de Concentração: Reumatologia

Orientadora: Profa. Dra. Rosa Maria Rodrigues Pereira

Co-orientador: Clovis Artur Almeida da Silva

São Paulo

2007 
Dados Internacionais de Catalogação na Publicação (CIP)

Preparada pela Biblioteca da

Faculdade de Medicina da Universidade de São Paulo

Creprodução autorizada pelo autor

Santiago, Rosabraulia Accioly

Avaliação do metabolismo ósseo e composição corporal em pacientes com dermatomiosite juvenil / Rosabraulia Accioly Santiago. -- São Paulo, 2007.

Tese(doutorado)--Faculdade de Medicina da Universidade de São Paulo.

Departamento de Clínica Médica.

Área de concentração: Reumatologia.

Orientadora: Rosa Maria Rodrigues Pereira.

Co-orientador: Clovis Artur Almeida da Silva

Descritores: 1.Dermatomiosite 2.Densidade óssea 3.Composição corporal 4.Osso/metabolismo 5.Criança 6.Adolescente

USP/FM/SBD-039/07 


\section{AGRADECI MENTOS}

Aos meus pais e irmãos, pelo grande apóio que sempre me deram em toda a minha vida.

Aos meus sogros pela torcida e apoio.

Ao meu marido, Renato, pelas horas em frente ao computador.

À Dra. Rosa Maria, uma orientadora muito perseverante.

Ao Dr. Clovis, um excelente amigo e chefe.

À Valeria, uma grande ajuda com um grande sorriso.

Às doutoras Adriana Maluf, Lúcia Campos, Bernadete Liphaus e Paola Lolito, pelo aprendizado e amizade no serviço de Reumatologia Pediátrica do Instituto da Criança.

Aos amigos da Reumatologia Pediátrica: Beth, Pollyana, Ana Júlia, Luciana, Mércia, Marília, Ricardo, Georgiana, Nadyesda, Daniela, Aline Islabão, Adriana Jesus, Carlos, Nádia, Kátia, Renata e Aline Miranda por compartilharmos amizade e conhecimento.

À Marisa, bibliotecária do Instituto da Criança, pela enorme ajuda no levantamento bibliográfico.

Às funcionárias do laboratório de Metabolismo Ósseo, pela colaboração.

Às funcionárias da Reumatologia, particularmente à Fátima, pela colaboração. 


\section{SUMÁRIO}

Resumo

Summary

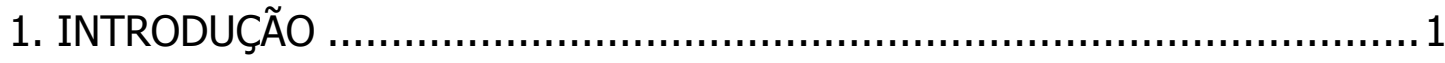

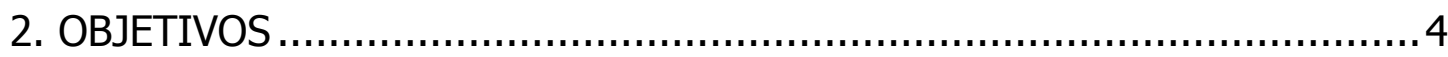

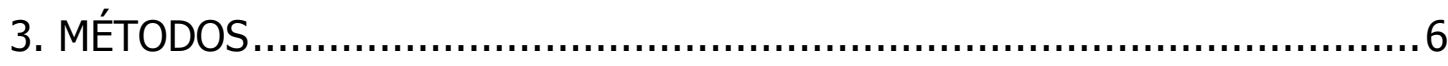

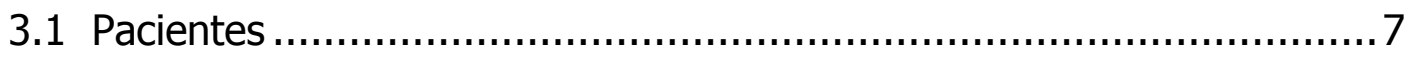

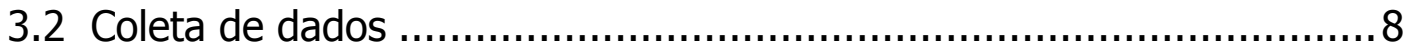

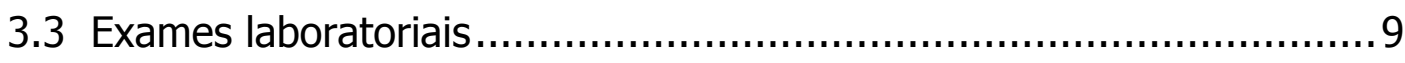

3.3.1 Parâmetros do metabolismo ósseo ............................. 9

3.3.2 Parâmetros laboratoriais de atividade inflamatória e muscular ... 10

3.4 Densitometria de dupla emissão de fontes de Raios-X .................. 11

3.5 Análise Estatística .................................................. 12

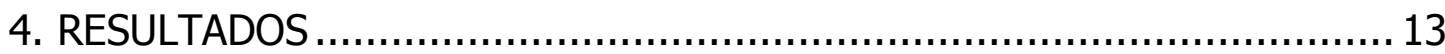

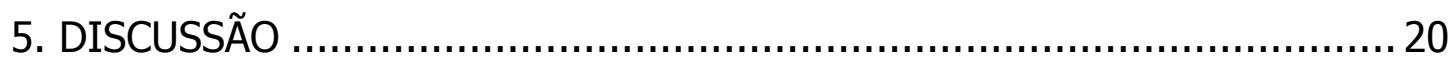

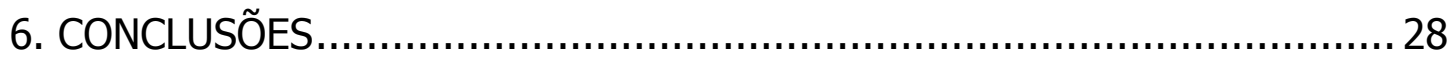

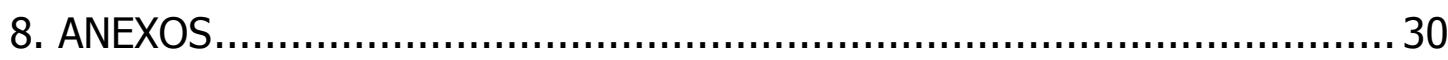

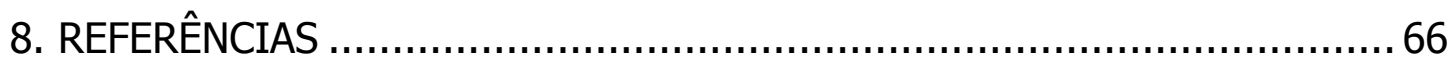




\section{RESUMO}

Santiago RA. Avaliação do metabolismo ósseo e composição corporal em pacientes com dermatomiosite juvenil [tese]. São Paulo: Faculdade de Medicina, Universidade de São Paulo. 2007. 72p.

Objetivo: Analisar a densidade mineral óssea (DMO) em pacientes com Dermatomiosite Juvenil (DMJ) e sua possível associação com composição corporal, atividade e duração de doença, uso de glicocorticóide (GC) e parâmetros bioquímicos do metabolismo ósseo (incluindo sistema osteoprotegerina (OPG)/RANKL). Métodos: Vinte pacientes do sexo feminino com DMJ e vinte controles pareados pela idade e sexo foram selecionados neste estudo. A DMO foi analisada pela densitometria de emissão dupla de Raios-X (DXA) e calculada a densidade mineral óssea aparente (DMOA). A composição corporal (massa magra e massa gorda) também foi analisada pela DXA. O tempo de doença, dose diária e cumulativa de GC foram obtidos em todos os pacientes através da revisão de prontuários. A atividade de doença e força muscular foram medidas através dos índices: Escore de Atividade de Doença (DAS: Disease Activity Score), Escala de Avaliação da Miosite na Infância (CMAS: Childhood Myositis Assessment Scale) e Teste Manual Muscular (MMT: Manual Muscle Testing). Parâmetros laboratoriais de inflamação e do metabolismo ósseo também foram estudados. OPG e RANKL foram medidos por ELISA tanto em pacientes com DMJ quanto nos controles. Resultados: Uma menor DMOA foi encontrada em pacientes com DMJ quando comparada com controles, na região de colo de fêmur $(0,302 \pm$ 0,059 vs. $\left.0,373 \pm 0,049 \mathrm{~g} / \mathrm{cm}^{3}, P<0,001\right)$, fêmur total $(0,128 \pm 0,022$ vs. $\left.0,155 \pm 0,019 \mathrm{~g} / \mathrm{cm}^{3}, P<0,001\right)$ e corpo total sem cabeça $(0,657 \pm 0,135 \mathrm{vs}$. $\left.0,776 \pm 0,120 \mathrm{~g} / \mathrm{cm}^{3}, \quad P=0,005\right)$. Interessantemente a análise da composição corporal demonstrou uma menor massa magra em pacientes com DMJ em relação aos controles $(24,04 \pm 7,38$ vs $30,08 \pm 7,66 \mathrm{~kg}$, $P=0,015)$, não havendo diferença em relação à massa gorda $(16,13 \pm 7,19$ vs. $14,82 \pm 7,17 \mathrm{~kg}, P=0,565)$. Uma tendência a menores valores séricos de cálcio também foram observados em pacientes com DMJ comparados com controles $(9,60 \pm 0,27$ vs $9,80 \pm 0,43 \mathrm{mg} / \mathrm{dl}, P=0,050)$, enquanto todos os parâmetros analisados, incluído OPG e RANKL foram semelhantes nos dois grupos $(P>0,05)$. A análise de regressão linear múltipla em pacientes com DMJ demonstrou a massa magra e 0 uso de pulsoterapia de metilprednisolona são fatores independentes para a DMOA na região de colo de fêmur e fêmur total $(P<0,05)$. Conclusão: $O$ presente estudo identificou que a baixa massa magra e o uso de pulsoterapia com GC são os fatores mais importantes associados com baixa DMOA na região do quadril em pacientes com DMJ enfatizando a necessidade de um melhor enfoque muscular terapêutico e o uso criterioso da pulsoterapia de GC na tentativa de prevenir a perda de massa óssea nestes pacientes.

Descritores: 1.Dermatomiosite 2.Densidade óssea 3.Composição corporal 4.Osso/metabolismo 5.Criança 6.Adolescente 


\section{SUMMARY}

Santiago RA. Bone mineral metabolism and body composition in Juvenile Dermatomyositis [thesis]. São Paulo: "Faculdade de Medicina, Universidade de São Paulo". 2007. 72p.

Objective. To analyze bone mineral density (BMD) in Juvenile Dermatomyositis (JDM) and its possible association with body composition, disease activity, duration of disease, glucocorticoid (GC) use and biochemical bone parameters (including osteoprotegerin and RANKL). Methods. Twenty girls with JDM and 20 controls gender- and age-matched were selected for the study. BMD was analyzed by dual energy X-ray absorptiometry (DXA) and bone mineral apparent density (BMAD) was calculated. Body composition (lean and fat mass) was also analyzed using DXA. Duration of disease, mean daily and cumulative steroid doses were calculated on the basis of their medical charts. Disease activity and muscle strength were measured by Disease Activity Score (DAS), Childhood Myositis Assessment Scale (CMAS), and Manual Muscle Testing (MMT). Inflammatory and bone metabolism parameters were also analyzed. Osteoprotegerin (OPG) and RANKL were measured in patients and controls, using ELISA. Results. A lower BMAD in femoral neck $\left(0.302 \pm 0.059\right.$ vs. $\left.0.373 \pm 0.049 \mathrm{~g} / \mathrm{cm}^{3}, P<0.001\right)$, total femur $\left(0.128 \pm 0.022\right.$ vs. $\left.0.155 \pm 0.019 \mathrm{~g} / \mathrm{cm}^{3}, P<0.001\right)$ and whole body without head $\left(0.657 \pm 0.135\right.$ vs. $\left.0.776 \pm 0.120 \mathrm{~g} / \mathrm{cm}^{3}, P=0.005\right)$ was observed in JDM compared to controls. Interestingly, body composition showed a lower lean mass in JDM when compared to controls ( $24.04 \pm 7.38$ vs. $30.08 \pm 7.66$ $\mathrm{kg}, P=0.015)$, but no difference was observed related to fat mass (16.13 \pm 7.19 vs. $14.82 \pm 7.17 \mathrm{~kg}, P=0.565)$. A trend of lower serum calcium was observed in JDM compared to controls $(9.60 \pm 0.27$ vs. $9.80 \pm 0.43 \mathrm{mg} / \mathrm{dl}$, $P=0.050$ ), whereas all other parameters analyzed, including OPG and RANKL, were similar ( $P>0.05)$. Multiple linear regression analysis revealed that, in JDM, lean mass and GC pulse therapy use were independent factors for BMAD in femoral neck and total femur $(P<0.05)$. Conclusion. The present study identifies that low lean mass and GC pulse therapy are the major factors for low femur BMAD in JDM patients emphasizing the need for better muscular therapeutic approach and spare GC pulse therapy use in order to prevent hip bone loss.

Descriptors: 1.Dermatomyositis 2.Bone density 3.body composition 4.Bone/metabolism 5.Children 6.Adolescent 
1. I NTRODUÇÃO 
Pacientes com doenças reumáticas, entre elas a Dermatomiosite Juvenil freqüentemente apresentam baixa massa óssea. Isto pode ser secundário ao processo inflamatório crônico da doença ou em decorrência da terapêutica, principalmente ao uso de glicocorticóides (Perez et al, 1994; Falcini et al, 1996; Pepmueller et al, 1996; Pereira et al, 1998; Cassidy JT, 1999). Uma grande parte destas crianças e adolescentes se encontra na fase pré-púbere tardia ou no início da puberdade, onde a formação óssea é muito rápida, e a baixa aquisição de massa óssea pode levar a osteoporose e suas complicações na vida adulta.

Existem diversos fatores implicados no desenvolvimento da osteoporose nas doenças imune-inflamatórias entre eles: tempo e gravidade de doença, imobilização, atividade física, uso de glicocorticóides, nutrição (Pereira et al, 1998; Cassidy JT, 1999; Lien et al, 2005; Hansen et al, 1998; Kipen et al, 1997).

Além disso, dados de literatura demonstram que o peso é um fator importante na densidade mineral óssea em crianças e adultos (Cassidy JT, 1999; Khan et al, 2004; Pereira et al, 1998), entretanto a contribuição da massa magra, massa gorda ou os dois componentes na aquisição e manutenção da densidade mineral necessita de melhores estudos. 
O desenvolvimento da densitometria por dupla emissão de Raios-X (DXA), que é um método preciso, rápido e de baixa radiação, tem facilitado o estudo da massa óssea e composição corporal em pacientes com doenças crônicas (Genant et al, 1996; Brambilla et al, 2000; Kipen et al,1998). Embora a DMO seja a medida de escolha, ela é influenciada pelo tamanho do corpo e não representa a verdadeira densidade volumétrica. Na tentativa de reduzir o efeito do tamanho do osso na medida da DMO areal, várias estimativas da densidade óssea volumétrica têm sido propostas, entre elas a densidade mineral óssea aparente. (Carter et al, 1992).

As doenças crônicas geralmente comprometem estes dois componentes, assim o objetivo deste estudo foi analisar a densidade mineral óssea (DMO) em pacientes com DMJ comparando com crianças e adolescentes saudáveis, e sua possível associação com a composição corporal (comprometimento da massa magra e massa gorda), atividade e duração de doença, uso de glicocorticóide e parâmetros bioquímicos gerais e ósseos [incluindo sistema osteoprotegerina (OPG)/RANKL]. 
2. OBJ ETIVOS 
1. Analisar a densidade mineral óssea aparente (DMOA) e composição corporal em pacientes com Dermatomiosite Juvenil (DMJ) comparando com crianças e adolescentes saudáveis pareados por idade e sexo.

2. Analisar a associação da DMOA com:

- composição corporal,

- atividade e duração de doença,

- uso de glicocorticóide,

- parâmetros bioquímicos do metabolismo ósseo (incluindo sistema osteoprotege-rina [OPG]/RANKL). 
3. MÉTODOS 


\subsection{Pacientes}

Vinte pacientes do sexo feminino com diagnóstico de DMJ segundo os critérios de Bohan e Peter (Bohan \& Peter, 1975) e vinte crianças e adolescentes saudáveis (controles) pareados por idade e sexo foram selecionados para o estudo. Todos os pacientes eram acompanhados na Divisão de Reumatologia do Hospital das Clínicas da Faculdade de Medicina da Universidade de São Paulo e na Unidade de Reumatologia Pediátrica do Instituto da Criança.

O grupo controle consistiu de crianças e adolescentes saudáveis recrutadas das famílias dos pacientes com DMJ (irmãs ou primas), com o objetivo de minimizar as diferenças em alguns fatores de risco para baixa massa óssea, como estilo de vida, nutrição, fatores genéticos e constitucionais.

\section{Critérios de Exclusão}

Causas secundárias de baixa massa óssea foram excluídas em pacientes e controles, entre elas, história clínica de má-absorção, insuficiência renal ou hepática, hipertiroidismo ou hipotiroidismo, tabagismo, uso de glicocorticóides (nos controles) e uso de outros medicamentos que comprometessem o metabolismo ósseo. 


\subsection{Coleta de dados}

Dados demográficos e antropométricos foram obtidos por entrevista, exame físico nas pacientes e controles, tais como: idade em anos, peso em quilogramas, altura em centímetros, estádio puberal de Tanner (Tanner JM, 1962), idade da menarca em anos e presença de amenorréia (ausência de ciclos menstruais por um período superior a 4 meses).

A ingestão de cálcio foi determinada por uma entrevista individual utilizando um questionário alimentar detalhado (disponível no Osteoporosis Society Canada website, www.osteoporosis.ca) nos pacientes com dermatomiosite juvenil e nos controles.

Dados clínicos incluindo tempo de duração e atividade de doença, uso de glicocorticóide (dose diária em miligramas, dose cumulativa em gramas, uso de pulsoterapia com metilprednisolona), uso de metotrexate foram obtidos através de revisão de prontuários e entrevista.

Nos pacientes com dermatomiosite juvenil, a atividade da doença e força muscular foram medidas através do Escore de Atividade de Doença (DAS: Disease Activity Score), da Escala de Miosite na Infância (CMAS: Childhood Myositis Assessment Scale) e do Teste de Avaliação da Força Muscular Manual (MMT: Manual Muscle Testing) (Bode et al, 2003; Lovell et al, 1999; Florence et al, 1992). 
O DAS avalia o envolvimento de pele (pontuação de 0 a 9) e o comprometimento muscular (pontuação de 0 a 11) tendo um escore total de 20 (Bode et al, 2003).

O CMAS foi validado como um instrumento para avaliar força e função muscular. Um escore é dado para cada um dos 14 exercícios tendo um escore máximo de 53 (Lovell et al, 1999).

O Teste de Avaliação da Força Muscular Manual (MMT) é um outro instrumento que a avalia a função de oito grupos musculares (flexores do pescoço, detóide médio, bíceps braquial, extensão do punho, gluteus maximus, gluteus medius, quadríceps e dorsiflexão dos tornozelos) com um escore total de 80 (Florence et al, 1992).

A presença de calcinose foi avaliada, particularmente em coluna lombar e fêmur total.

\subsection{Exames laboratoriais}

\subsubsection{Parâmetros do metabolismo ósseo}

Parâmetros laboratoriais do metabolismo ósseo como cálcio e fósforo sérico, fosfatase alcalina, cálcio urinário de 24 horas foram dosados em todos pacientes e controles, no Laboratório Central do Hospital das Clinicas da FMUSP, utilizando métodos laboratoriais de rotina. 
O soro para medida da osteoprotegerina sérica (OPG), SRANKL (soluble receptor activator of nuclear factor KB ligand) de pacientes e controles foi coletado em jejum e estocado a $-80^{\circ} \mathrm{C}$ no Laboratório de Metabolismo Ósseo (LIM-17) para posterior análise.

Níveis séricos de OPG foram medidos por ELISA (Biomédica, Viena, Áustria), de acordo com as instruções do fabricante, que utiliza um anticorpo anti-OPG monoclonal para capturar a OPG do soro. A OPG capturada foi detectada por um anticorpo anti-OPG policlonal, biotinilado e o substrato tetrametilbenzidina (TMB). O limite de detecção deste ensaio é $2,8 \mathrm{pg} / \mathrm{ml}$ (Bezerra et al, 2005a).

Níveis séricos de SRANKL não complexado (livre) foram medidos por enzima imuno-ensaio (sRANKL, Biomédica, Viena, Áustria). De acordo com o protocolo do fabricante, a amostra e o anticorpo de detecção anti-sRANKL policlonal, biotinilado, foram pipetados nos poços. O sRANKL humano, se presente no soro, ligava-se a OPG recombinante e formava um sanduíche com o anticorpo de detecção. O TMB foi adicionado à reação como substrato. 0 limite deteç̧ão deste ensaio foi 1,6 pg/ml (Bezerra et al, 2005a).

\subsubsection{Parâmetros laboratoriais de atividade inflamatória e muscular}

Exames laboratoriais de atividade de doença como velocidade de hemossedimentação (VHS), proteína C reativa (PCR) e enzimas musculares: creatinoquinase (CK), aldolase foram analisados em todos os pacientes. Estes parâmetros laboratoriais foram considerados alterados quando PCR> 5ug/dl, VHS> 13 mm, CPK> $173 \mathrm{U} / \mathrm{L}$ e aldolase >7,6 U/L. 


\subsection{Densitometria de dupla emissão de fontes de Raios-X}

A densidade mineral óssea (DMO) foi analisada por DXA utilizando um densitômetro Hologic QDR 2000. Para minimizar os efeitos de confusão do tamanho do esqueleto na medida da DMO, foi calculada a densidade mineral óssea aparente (DMOA) que reflete a densidade volumétrica. O cálculo da densidade volumétrica foi obtido segundo a equação: $\mathrm{DMOA}$ = DMO dividida pela raiz quadrada da área óssea a ser analisada (Cvijetic \& Korsic, 2004). A DMOA foi obtida na região de coluna lombar (L1-L4), colo de fêmur, fêmur total e corpo inteiro. Na análise do corpo inteiro, a cabeça dos pacientes e controles foi excluída uma vez que para crianças abaixo de 9 anos, ela contribui para uma variabilidade maior que a idade (Taylor et al, 1997).

A composição corporal: massa magra e massa gorda, também foram analisados utilizando-se um software pediátrico no mesmo densitômetro Hologic QDR-2000.

Este estudo foi aprovado pela comissão de ética do Hospital das Clínicas da FMUSP (CAPPESQ 078/04) e o termo de consentimento informado foi obtido dos pais e/ou pacientes com DMJ e controles saudáveis. 


\subsection{Análise Estatística}

Dados numéricos foram descritos como média e desvio padrão ou porcentagem. Variáveis antropométricas, demográficas, laboratoriais, densidade mineral óssea aparente (DMOA) e composição corporal foram comparadas entre pacientes e controles utilizando o teste t-Student não pareado ou teste não paramétrico de Mann-Whitney. As variáveis estádio de Tanner $\geq$ M2, percentil de peso $\leq 25$, percentile de altura $\leq 25$ foram comparadas em pacientes e controles usando teste exato de Fischer.

Apenas para o grupo de pacientes foram calculadas as correlações de Pearson para saber quais as variáveis correlacionadas com os valores da DMOA. Com base nos resultados obtidos das correlações de Pearson, foram realizadas regressões lineares múltipla de cada uma das medidas da DMOA (colo de fêmur, fêmur total, corpo inteiro sem cabeça) com as medidas que apresentaram correlações estatisticamente significativas para estabelecer a relação existente entre elas.

Os testes foram realizados ao nível de significância de $5 \%$. Todas as análises estatísticas foram realizadas utilizando SPSS Windows, versão 11,0 (SSPC, Chicago, IL). 
4. RESULTADOS 
As características demográficas e antropométricas das pacientes e controles são mostradas na tabela 1. A média da idade das pacientes e controles no momento do estudo foi de 13,47 e 13,49 anos, respectivamente $(p=0,985)$. Não houve diferença nos dados antropométricos, entre pacientes e controles, em relação ao peso e a altura $(P>0,05)$, no entanto, $35 \%$ dos pacientes com DMJ encontravam-se abaixo do percentil 25 em relação ao peso, em comparação com $5 \%$ do grupo controle $(P=0,044)$. Semelhantemente, $60 \%$ das DMJ e $10 \%$ do grupo controle encontravam-se abaixo do percentil 25 em relação a altura $(P=0,002)($ Tabela 1).

Em relação ao estádio puberal de Tanner, $90 \%$ das pacientes com DMJ e $80 \%$ do grupo controle eram púberes (apresentaram estádios M2P2, M3P3, M4P4, M5P5) $(P=0,661)$. Doze (60\%) pacientes com DMJ e 13 (65\%) controles já haviam apresentado a menarca e nenhuma destas pacientes ou controles apresentavam-se amenorréicas na entrada do estudo. Não houve diferença na idade da menarca nos dois grupos avaliados $(12,09 \pm 1,45$ vs. $11,62 \pm 0,96, P=0,234)$ (Tabela 1$)$.

A ingestão de cálcio na dieta associada à suplementação oral foi maior nos pacientes com DMJ comparado com controles $(1160 \pm 393,57 \mathrm{mg} / \mathrm{dia}$ vs. 
$680 \pm 320,94 \mathrm{mg} / \mathrm{dia}, P<0,0001)$ (Tabela 1). Doze (60\%) pacientes com DMJ faziam uso de suplementação de cálcio, enquanto nenhum controle usava suplementação.

Tabela 1 - Características demográficas, antropométricas, ingestão de cálcio em pacientes com Dermatomiosite juvenil (DMJ) e controles. Dados expressos em média e desvio-padrão e porcentagem

\begin{tabular}{lccc}
\hline & $\begin{array}{c}\text { DMJ } \\
(\mathrm{n}=20)\end{array}$ & $\begin{array}{c}\text { Controle } \\
(\mathrm{n}=20)\end{array}$ & $P$ \\
\hline Idade (anos) & $13,47 \pm 4,24$ & $13,49 \pm 4,12$ & 0,985 \\
Peso (Kg) & $42,62 \pm 13,30$ & $48,05 \pm 14,44$ & 0,224 \\
Peso < 25 percentil, $\mathrm{n}(\%)$ & $7(35)$ & $1(5)$ & $\mathbf{0 , 0 4 4}$ \\
Altura (cm) & $142,70 \pm 16,92$ & $149,90 \pm 14,27$ & 0,154 \\
Altura < 25 percentil, $\mathrm{n}(\%)$ & $12(60)$ & $2(10)$ & $\mathbf{0 , 0 0 2}$ \\
Estádio de Tanner $\geq \mathrm{M} 2, \mathrm{n}(\%)$ & $18(90)$ & $16(80)$ & 0,661 \\
Idade de menarca (anos)* & $12,09 \pm 1,45$ & $11,62 \pm 0,96$ & 0,234 \\
Ingestão de cálcio (mg/dia) & $1160 \pm 393,57$ & $680 \pm 320,94$ & $<\mathbf{0 , 0 0 1}$
\end{tabular}

* Apenas 12 DMJ e 13 controles já haviam apresentado menarca.

O tempo médio de duração da doença foi $46,50 \pm 31,49$ meses. Seis (30\%) pacientes apresentavam calcinose (ureter, quadril, cotovelo, braços, pescoço, joelho). Nenhuma das pacientes apresentava calcinose na região que comprometesse a avaliação da massa óssea na região de coluna lombar e quadril direito. 
Em relação as médias dos escores de atividade e força muscular encontrou-se: 3,70 para o DAS; 45,20 para o CMAS e 75,60 para o MMT. Nove (45\%) pacientes com DMJ apresentavam aldolase elevada e quatro (20\%) pacientes creatinoquinase (CK) aumentada na entrada do estudo (Tabela 2).

A dose cumulativa de glicocorticóide foi $17,42 \pm 10,27 \mathrm{~g}$, a dose média de GC foi de $55,88 \pm 10,66 \mathrm{mg} /$ dia e $50 \%$ das DMJ haviam feito uso de pulsoterapia de glicocorticóide e $70 \%$ uso de methotrexate (Tabela 2).

Tabela 2 - Características clínicas, escores de atividade e força muscular, parâmetros laboratoriais inflamatórios e musculares, e terapêutica utilizada em pacientes com Dermatomiosite juvenil (DMJ). Dados expressos em média e desvio-padrão e porcentagem

DMJ

$(n=20)$

Tempo de doença (meses)

Calcinose, n (\%)

DAS (escore, 0-20)

CMAS (escore, 0-53)

MMT (escore, 0-80)

VHS, $\mathrm{mm} / 1^{\mathrm{a}}$ hora

PCR, mcg/DI

CK elevada, $\mathrm{n}(\%)$

Aldolase elevada, $\mathrm{n}(\%)$

Dose cumulativa de GC (g)

Pulsoterapia com GC, n(\%)

Uso de metotrexate, n (\%)

$$
46,50 \pm 31,49
$$

$$
3,70 \pm 4,90
$$$$
45,20 \pm 10,32
$$$$
75,60 \pm 5,95
$$$$
16,10 \pm 7,20
$$$$
2,06 \pm 2,02
$$

$$
17,42 \pm 10,27
$$

$10(50)$

$14(70)$

DAS- escore de atividade de doença, CMAS- escala de avaliação da miosite na infância, MMT- teste manual muscular, VHS- velocidade de hemossedimentação, PCRproteína $\mathrm{C}$ reativa, $\mathrm{CK}$ - creatinoquinase, GC- glicocorticóide 
Uma tendência a menores valores séricos de cálcio foi encontrada em pacientes com DMJ comparados com controles (9,60 \pm 0,27 vs. 9,80 $\pm 0,43$ $\mathrm{mg} / \mathrm{dl}, P=0,050)$. Não houve diferença em relação ao fósforo, fosfatase alcalina, calciúria de 24 hs, OPG e sRANKL nos dois grupos analisados (P>0,05) (Tabela 3).

Tabela 3 - Parâmetros laboratoriais do metabolismo ósseo: cálcio, fósforo, fosfatase alcalina, calciúria de 24 hs, Osteoprotegerina (OPG), sRANKL, em pacientes com Dermatomiosite juvenil (DMJ) e controles. Dados expressos em média e desvio-padrão

\begin{tabular}{lccc}
\hline & $\begin{array}{c}\text { DMJ } \\
(\mathrm{n}=20)\end{array}$ & $\begin{array}{c}\text { Controle } \\
(\mathrm{n}=20)\end{array}$ & $P$ \\
\hline Cálcio sérico (mg/dl) & $9,60 \pm 0,27$ & $9,80 \pm 0,43$ & 0,050 \\
Fósforo (mg/dl) & $4,60 \pm 0,69$ & $4,48 \pm 0,71$ & 0,591 \\
Fosfatase Alcalina (U/L) & $117,11 \pm 59,52$ & $152,55 \pm 85,57$ & 0,137 \\
Calciúria 24h (mg/kg/24h) & $2,15 \pm 1,15$ & $2,69 \pm 1,31$ & 0,215 \\
OPG (pg/ml) & $38,19 \pm 26,71$ & $29,31 \pm 32,92$ & 0,355 \\
sRANKL (pg/ml) & $4,72 \pm 3,59$ & $4,57 \pm 4,01$ & 0,899 \\
OPG/RANKL & $11,57 \pm 12,87$ & $11,69 \pm 16,50$ & 0,979 \\
\hline
\end{tabular}

A DMOA estava diminuída nas pacientes com $\mathrm{DMJ}$ em relação aos controles em colo de fêmur $\left(0,302 \pm 0,059\right.$ vs. 0,373 $\pm 0,049 \mathrm{~g} / \mathrm{cm}^{3}$, $P<0,001)$, fêmur total $\left(0,128 \pm 0,022\right.$ vs. $\left.0,155 \pm 0,019 \mathrm{~g} / \mathrm{cm}^{3}, P<0,001\right)$ e corpo inteiro sem cabeça $\left(0,657 \pm 0,135\right.$ vs. $\left.0,776 \pm 0,120 \mathrm{~g} / \mathrm{cm}^{3}, P=0,005\right)$ 
(Tabela 4). Não foi observada diferença na DMOA, entre pacientes e controles, na região de coluna lombar $(P>0,05)$.

Na análise da composição corporal observou-se uma menor massa magra $(24,04 \pm 7,38$ vs. $30,08 \pm 7,66 \mathrm{~kg}, \mathrm{P}=0,015)$ nas pacientes em relação aos controles, porém não houve diferença em relação à massa gorda $(16,13 \pm 7,19 \mathrm{~kg}$ vs. $14,82 \pm 7,17 \mathrm{~kg}, P=0,565)$ (Tabela 4).

Tabela 4 - Valores de densidade mineral óssea aparente (DMOA) na coluna lombar (L1-L4), colo de fêmur, fêmur total, corpo inteiro sem cabeça e composição corporal (massa magra e massa gorda) em pacientes com Dermatomiosite juvenil (DMJ) e controles. Dados expressos em média e desvio-padrão

\begin{tabular}{lccc}
\hline & $\begin{array}{c}\text { DMJ } \\
(\mathrm{n}=20)\end{array}$ & $\begin{array}{c}\text { Controle } \\
(\mathrm{n}=20)\end{array}$ & $P$ \\
\hline DMOA- L1-L4 $\left(\mathrm{g} / \mathrm{cm}^{3}\right)$ & $0,115 \pm 0,045$ & $0,117 \pm 0,016$ & 0,809 \\
DMOA- colo de fêmur $\left(\mathrm{g} / \mathrm{cm}^{3}\right)$ & $0,302 \pm 0,059$ & $0,373 \pm 0,049$ & $<\mathbf{0 , 0 0 1}$ \\
DMOA- fêmur total $\left(\mathrm{g} / \mathrm{cm}^{3}\right)$ & $0,128 \pm 0,022$ & $0,155 \pm 0,019$ & $<\mathbf{0 , 0 0 1}$ \\
DMOA- corpo inteiro $\left(\mathrm{g} / \mathrm{cm}^{3}\right)$ & $0,657 \pm 0,135$ & $0,776 \pm 0,120$ & $\mathbf{0 , 0 0 5}$ \\
Massa magra $(\mathrm{Kg})$ & $24,04 \pm 7,38$ & $30,08 \pm 7,66$ & $\mathbf{0 , 0 1 5}$ \\
Massa gorda $(\mathrm{Kg})$ & $16,13 \pm 7,19$ & $14,82 \pm 7,17$ & 0,565 \\
\hline
\end{tabular}

Nos pacientes com DMJ, a análise de regressão linear múltipla utilizando a DMOA (colo de fêmur, fêmur total e corpo inteiro sem cabeça) como variável dependente, e como variáveis independentes aquelas que 
apresentassem correlação $(p<0,20)$, foram demonstradas associação da DMOA com massa magra e pulsoterapia com GC na região de colo de fêmur e fêmur total (Tabela 5). Nenhuma correlação foi demonstrada em relação a DMOA na região de corpo inteiro e as demais variáveis independentes.

Tabela 5 - Análise de regressão linear múltipla utilizando como variáveis dependentes a DMOA em colo de fêmur e fêmur total, e como variáveis independentes aquelas que apresentassem correlações com significância menor que $0,20(p<0,20)$

Coeficiente $\beta \quad$ Erro padrão $\quad P$

\begin{tabular}{lcccr}
\hline & Constante & 0,19 & 0,031 & $<\mathbf{0 , 0 0 1}$ \\
$\begin{array}{l}\text { DMOA colo de } \\
\text { fêmur }\left(\mathrm{g} / \mathrm{cm}^{3}\right)\end{array}$ & Massa magra (Kg) & 0,006 & 0,001 & $<\mathbf{0 , 0 0 1}$ \\
& Pulsoterapia GC & 0,043 & 0,017 & $\mathbf{0 , 0 2 4}$ \\
\hline \multirow{2}{*}{$\begin{array}{c}\text { DMOA fêmur } \\
\text { total }\left(\mathrm{g} / \mathrm{cm}^{3}\right)\end{array}$} & Massa magra (Kg) & 0,002 & 0,000 & $\mathbf{0 , 0 0 4}$ \\
& Pulsoterapia GC & $-0,022$ & 0,007 & $\mathbf{0 , 0 0 5}$ \\
\hline
\end{tabular}


5. DISCUSSÃO 
O presente estudo demonstrou uma diminuição da densidade mineral óssea volumétrica em pacientes com dermatomiosite juvenil quando comparada com controles saudáveis pareados pela idade e gênero, comprometendo a região de colo de fêmur, fêmur total e corpo inteiro.

Poucos trabalhos na literatura analisaram a massa óssea em crianças com DMJ demonstrando uma diminuição da densidade mineral óssea, principalmente na região de coluna, nestas crianças e adolescentes (Stewart et al, 2003; Alsufyani et al, 2005; Castro et al, 2005).

Diferente do presente estudo, estes autores (Stewart et al, 2003; Alsufyani et al, 2005; Castro et al, 2005) analisaram a densidade areal e não a volumétrica e assim os resultados obtidos não foram corrigidos pelo tamanho do osso destes pacientes.

A DXA fornece apenas duas medidas dimensionais do conteúdo mineral ósseo e área óssea para um osso tridimensional. Deste modo, a DMO analisada pela DXA não é uma medida da densidade volumétrica $\left(\mathrm{g} / \mathrm{cm}^{3}\right)$ porque não fornece informação sobre a profundidade óssea. Ossos com maior largura e altura são também mais espessos. Assim, ossos com a mesma DMO volumétrica, mas que variam de tamanho irão diferir em relação a densidade mineral óssea areal. Ossos de tamanho 
menor irão apresentar uma menor DMO areal que ossos maiores, uma vez que a espessura óssea não é computada nos resultados da análise por DXA. Crianças que são menores para sua idade poderão apresentar valores inferiores da DMO areal quando comparadas com crianças da mesma idade com desenvolvimento pondero-estatural normal, mesmo com sua DMO volumétrica idêntica (Crabtree et al, 2007; Cvijetic \& Korsic, 2004).

Devido a estes fatores de confusão relacionados ao tamanho ósseo e como estas crianças e adolescentes com DMJ geralmente apresentam desenvolvimento pondero-estatural menor em relação a crianças da mesma faixa etária, no presente trabalho utilizamos a densidade mineral óssea aparente, a qual reflete a densidade volumétrica tornando análise da massa óssea mais confiável (Carter et al, 1992; Cvijetic \& Korsic M, 2004; Bachrach et al, 1999; Wang MC et al, 1997).

Diferente de trabalhos anteriores de literatura, a densidade mineral óssea na região de coluna (L1-L4) de nossos pacientes não diferiu em relação aos controles e isso pode ser devido à análise da densidade volumétrica em nossa casuística, em contrapartida a análise da densidade areal realizada pelos demais autores (Stewart et al, 2003; Alsufyani et al, 2005; Castro et al, 2005).

Em nossos pacientes com DMJ encontramos uma tendência a menores valores séricos de cálcio comparado com controles saudáveis apesar dos mesmos estarem dentro dos níveis da normalidade. Estes achados podem 
estar associados a uma menor absorção do cálcio, secundário ao uso de medicações entre elas o GC e a uma menor síntese de vitamina D devido a uma menor exposição solar; uma vez que a ingestão de cálcio era até maior nos pacientes com DMJ.

Uma ingestão adequada de cálcio e vitamina D durante a infância e adolescência é fundamental para uma boa mineralização do esqueleto. Johnston et al demonstraram que a suplementação de cálcio facilita a taxa de aumento da DMO em crianças normais pré-puberes (Johnston et al, 1992). Warady, et al encontraram um significante aumento da DMO da coluna em crianças com doenças reumáticas quando receberam pelos menos 1 g de cálcio e 400 UI de vitamina D (Warady et al, 1994). Por outro lado, Reed et al, suplementando crianças com artrite reumatóide juvenil com $25(\mathrm{OH})$ vitamina $\mathrm{D}$ por um período de 1 ano, não observaram aumento da DMO neste período (Reed et al, 1991)

Osteoprotegerina, RANK e RANKL, membros da superfamília do fator de necrose tumoral tem sido implicados no metabolismo ósseo em diversas doenças inflamatórias crônicas (Bezerra et al, 2005b). RANKL interage com seu receptor RANK, na superfície de osteoclastos imaturos induzindo a formação de osteoclastos, ativação e sobrevivência destas células. A OPG (receptor solúvel) tem como função, competir com o RANK para a ligação com o RANKL. Consequentemente a OPG é um potente inibidor da maturação de osteoclastos e da ativação destas células in vivo e em vitro (Bezerra et al, 2005b; Kong et al, 2000). 
No presente estudo não houve diferença nos níveis séricos de OPG e RANKL nos pacientes comparado com controles pareados por idade e sexo. Citocinas inflamatórias relacionadas com dano muscular (como TNF-alfa, IL1) (Mackiewicz et al, 2003; Salomonsson et al, 2006) podem aumentar a produção da OPG pelos osteoblastos, células estromais e células endoteliais (Hofbauer et al, 2004) e contra balancearem a ação do glicorticóide que induziria a uma menor expressão da OPG e um aumento do RANKL.

Em relação à atividade de doença e a terapêutica com glicocorticóide os trabalhos são controversos na literatura. Stewart et al encontraram osteopenia em pacientes com DMJ, mesmo com a doença inativa e em pacientes sem uso de corticóide por um período de três a oito anos (Stewart et al, 2003). Estes autores concluíram que na DMJ devido a utilização de altas doses de corticóide, é freqüente o encontro de baixa densidade mineral óssea, sendo necessário um período de tempo maior para a normalização da massa óssea. Em contraste com pacientes com DMJ, outros autores demonstraram que pacientes com história de artrite reumatóide juvenil parecem atingir um pico de massa óssea normal (na região de coluna) na vida adulta, apesar da maioria destes pacientes terem doença ativa na puberdade (Haugen et al, 2000). Assim, pacientes com DMJ têm uma maior tendência a desenvolverem osteoporose na vida adulta em decorrência da baixa reserva óssea adquirida na adolescência e idade adulta jovem. (Stewart et al, 2003). 
Castro et al (Castro et al, 2005) medindo a densidade mineral óssea em dez meninas com DMJ também evidenciaram uma significante diminuição na densidade mineral óssea nestas pacientes quando comparada com controles, porém sem associação da densidade mineral óssea com atividade e tempo de doença, e uso de corticóide.

Alsufyani et al analisando a densidade mineral óssea em crianças com dermatomiosite juvenil, lupus eritematoso sistêmico juvenil e vasculite sistêmica demonstraram uma associação entre a DMO diminuída e dose cumulativa de GC e uma não associação com a atividade de doença (Alsufyani et al, 2005).

Em nosso trabalho não observamos correlação entre os escores de atividade/força muscular de doença, nem da dose cumulativa de GC com valores de densidade mineral óssea aparente nestas crianças com DMJ. Interessantemente, houve uma associação com o uso de pulsoterapia de GC com baixa massa óssea nestes pacientes. Recentemente, Haugeberg et al (Haugeberg et al, 2004) estudando 38 pacientes com doenças reumáticas sistêmicas, tratados com pulsoterapia de metilprednisolona por um período médio de 6 meses, demonstraram uma importante perda de massa óssea principalmente na região de colo de fêmur $(-2,2 \%)$, mas também em fêmur total $(-1,1 \%)$ e coluna lombar(-1,0\%). Surpreendentemente, estes autores não observaram diferença na perda de massa óssea entre aqueles indivíduos que utilizavam ou não GC oral (Haugeberg et al, 2004). 
Um outro achado interessante em nosso estudo foi a associação de massa magra com densidade mineral óssea aparente nestas crianças.

Vários trabalhos têm demonstrado que o peso corporal é o melhor preditor de massa óssea em crianças saudáveis (Bonjour et al, 1991; Theintz et al, 1992) e em crianças com doenças crônicas (Castro et al, 2005; Kotaniemi et al, 1999) e o baixo peso é um fator de risco importante para osteoporose, fraturas vertebrais e de quadril (Reid et al, 2002; Lim et al, 2004). No entanto, existem controversas de como a massa magra ou massa gorda; os dois componentes do peso corporal determinam a densidade mineral óssea.

De fato, em nosso estudo, o primeiro a analisar a composição corporal em pacientes com dermatomiosite juvenil, demonstrou pela análise de regressão linear que a baixa massa magra era um fator independente associado com a baixa densidade mineral óssea encontrada na região de colo de fêmur, fêmur total nestas crianças com DMJ.

Semelhante aos nossos achados, Lien et al em um estudo prospectivo longitudinal realizado com 100 crianças com artrite idiopática juvenil comparadas com 100 crianças saudáveis, foi evidenciado nos pacientes, um baixo ganho de conteúdo mineral ósseo associado com baixo ganho de massa magra. Estes autores concluíram que esta composição corporal alterada estava possivelmente relacionada com o processo inflamatório crônico e uma atividade física diminuída (Lien et al, 2005). 
Outros estudos têm demonstrado que além do processo inflamatório crônico, o uso de glicocorticóide pode ser responsável pela baixa densidade mineral óssea e alteração da composição corporal, levando a uma diminuição da massa magra com ou sem aumento da massa gorda (Mul et al, 2002; Kipen et al, 1998). O glicocorticóide inibe a síntese protéica e estimula a degradação de proteína no músculo esquelético, resultando em um catabolismo protéico e diminuição da massa muscular (Rebuffe-Scrive et al, 1998).

Em nossos pacientes com DMJ além da massa magra, o uso de glicocorticoide sob a forma de pulsoterapia foram fatores independentes para a baixa densidade mineral óssea na região de quadril concluindo que possivelmente o processo inflamatório muscular crônico na região de quadríceps associado a altas doses de GC foram os fatores mais importantes na diminuição de massa óssea neste sítio frequentemente envolvido nesta patologia.

Assim, o presente trabalho demonstrou que a diminuição da DMO é um problema sério e freqüente em crianças com DMJ e mais importante identificou que a baixa massa magra e o uso de pulsoterapia com metilprednisolona são os principais fatores associados com a baixa densidade mineral óssea na região de quadril nestas crianças enfatizando a necessidade de um melhor enfoque muscular terapêutico e o uso criterioso da pulsoterapia com GC na prevenção da perda de massa óssea nestes pacientes. 


\section{Resumo e Conclusões}

1. Pacientes com DMJ apresentaram baixa densidade mineral óssea aparente na região de colo de fêmur, fêmur total e corpo inteiro comparado com crianças e adolescentes pareados por idade e sexo.

2. Pacientes com DMJ apresentaram baixa massa magra comparadas com crianças e adolescentes pareados por idade e sexo. Não houve diferença em relação a massa gorda, nos dois grupos analisados.

3. A baixa massa magra e o uso de pulsoterapia com glicorticóide foram associados a baixa densidade mineral óssea aparente na região de colo de fêmur e fêmur total em pacientes com DMJ.

4. Medidas preventivas, incluindo um melhor enfoque muscular terapêutico e o uso criterioso da pulsoterapia com GC, são fundamentais para evitar a perda de massa óssea na região do quadril destas crianças e adolescentes com DMJ. 


\section{ANEXOS}




\title{
Anexo 1. Artigo original
}

\author{
TRABALHO ENVI ADO PARA PUBLI CACÃO
}

\section{BONE MINERAL APPARENT DENSITY IN JUVENILE DERMATOMYOSITIS: THE ROLE OF LEAN BODY MASS AND GLUCOCORTI COI D USE}

Rosabraulia A Santiago ${ }^{1}$, Clovis A A Silva ${ }^{2}$, Valéria F Caparbo ${ }^{1}$, Adriana S Maluf $^{2}$, Rosa M R Pereira ${ }^{1}$

Rheumatology Division (Bone Mineral Metabolism Laboratory) ${ }^{1}$ and Pediatric Rheumatology Unit of the Department of Pediatrics ${ }^{2}$, University of São Paulo, São Paulo, Brazil

Address reprints requests and correspondence to:

Rosa Maria Rodrigues Pereira

Disciplina de Reumatologia, Faculdade de Medicina da Universidade de São Paulo

Av. Dr Arnaldo, 455- $3^{\circ}$ andar- Reumatologia, sala 3107, São Paulo, SP, Brazil, CEP-01246-903

Phone: 5511 30617213, 551130617490

FAX: 551130617490

E-mail: rosamariarp@yahoo.com 


\section{Abstract}

Objective. To analyze bone mineral density (BMD) in Juvenile Dermatomyositis (JDM) and its possible association with body composition, disease activity, duration of disease, glucocorticoid (GC) use and biochemical bone parameters (including Osteoprotegerin and RANKL).

Methods. Twenty girls with JDM and 20 controls matched for gender- and age- were selected. Body composition and BMD were analyzed by DXA, and bone mineral apparent density (BMAD) was calculated. Duration of disease, cumulative and pulse therapy of GC were calculated based on medical records. Disease activity and muscle strength were measured by: Disease Activity Score, Childhood Myositis Assessment Scale and Manual Muscle Testing. Inflammatory and bone metabolism parameters were also analyzed. Osteoprotegerin (OPG) and RANKL were measured in patients and controls, using ELISA.

Results. A lower BMAD in femoral neck $(P<0.001)$, total femur $(P<0.001)$ and whole body $(P=0.005)$ was observed in JDM patients compared to controls. Body composition analysis showed a lower lean mass in JDM compared to $\operatorname{controls}(P=0.015)$, but not difference was observed related to fat mass. A trend of lower serum calcium was observed in $\operatorname{JDM}(P=0.05)$, whereas all other parameters analyzed, including OPG and RANKL, were similar. Multiple linear regression analysis revealed that, in JDM, lean mass $(P<0.01)$ and $G C$ pulse therapy use $(P<0.05)$ were independent factors for BMAD in hip region. 
Conclusion. The present study identifies that low lean mass and GC pulse therapy use are the major factors for low BMAD in JDM patients emphasizing the need for better muscular therapeutic approach and spare GC pulse therapy use in order to prevent hip bone loss.

Key words: juvenile dermatomyositis, bone mineral density, body composition, lean mass, glucocorticoid, Osteoprotegerin/RANKL.

Run title: Bone mass in Juvenile Dermatomyositis 


\section{I ntroduction}

Patients with rheumatic diseases, including Juvenile Dermatomyositis, often present low bone density. This may be secondary to the disease's chronic inflammatory response or stem from the therapeutic approach, particularly glucocorticoid use (1-5). The vast majority of such children and adolescents are at late pre-puberty or the onset of puberty, a phase during which bone formation is rapid and when low bone mass acquisition can lead to osteoporosis and complications thereof, in later life.

Several factors have been implicated in the development of osteoporosis in immuno-inflammatory diseases, including: disease duration and severity, immobilization, physical activity, nutrition and glucocorticoid use (1-5).

Furthermore, data from the literature show body mass to be an important factor in bone mineral density in both children and adults $(1,4,6)$. However, the contribution of lean mass, fat mass or a combination of these, in the acquisition and maintenance of mineral density requires further investigation.

The development of dual energy X-ray absorptiometry (DXA), an accurate, swift and low radiation method, has aided the study of bone mineral density (BMD) and body composition in such chronic patients (7-9). Although BMD is a measured of choice, it is influenced by body size and does not represent true volumetric density. In order to reduce the effect of bone body size on area BMD measurement, several estimates of volumetric bone density have been proposed, as bone mineral apparent density (10).

Given chronic diseases and glucocorticoid use tend to compromise body mass components; the objective of this study was to analyze bone mineral apparent density (BMAD) and body composition in JDM patients, and comparing these findings with healthy children and adolescents. In addition, association of BMAD with body composition (lean and fat mass compromise), disease activity, muscular strength and disease duration, glucocorticoid use 
and general biochemical and bone parameters [including the osteoprotegerin system (OPG)/RANKL] was also investigated.

\section{Materials and Methods}

\section{Patients}

Twenty female patients diagnosed with JDM according to Bohan and Peter's criteria (11), and twenty healthy children and adolescent controls matched for age and gender, were selected for the present study. All patients were followed within Rheumatology Division and in the Pediatric Rheumatology Unit, University of São Paulo, School of Medicine.

The healthy children and adolescents were recruited from the families of the JDM patients (either cousins or siblings) in order to minimize the differences in some of the risk factors for osteoporosis, such as lifestyle, nutrition, and constitutional and genetic factors.

Secondary causes of low bone mass were first ruled out in patients and controls, such as clinical history of poor absorption, renal or hepatic insufficiency, hyperthyroidism or hypothyroidism, smoking, glucocorticoid use (by controls) and use of bone metabolism suppressing drugs.

\section{Data collection}

Demographic and anthropometric data for patients and controls were obtained through interview and physical examination, where variables collected were: age in years, weight in kilograms, height in centimeters, Tanner's pubertal stage (breast and pubic hair) (12), age of menarche in years, and amenorrhea (absence of menstrual cycle for more than 4 months).

Calcium intake was determined by individual interview using a detailed food frequency questionnaire and calcium calculator (available on the Osteoporosis Society Canada website, www.osteoporosis.ca) in patients with JDM and controls. 
Clinical data included disease duration, glucocorticoid use (daily dose in milligrams, cumulative dose in grams and pulse therapy use), methotrexate use were taken from medical records and interview.

JDM disease activity and muscle strength was measured using: the Disease Activity Score (DAS), the Childhood Myositis Assessment Scale (CMAS) and the Manual Muscle Testing (MMT) (13-15).

The DAS is a 20-point scale comprising 2 subscales reflecting skin involvement (ranging from 0 to 9 ) and muscle inflammation (ranging from 0 to 11) (13). The CMAS has been validated as an assessment tool for muscle stamina and function, assigning a score for each of 14 exercises, giving a maximum total score of 53 (14). The Manual Muscle Testing (MMT) is another instrument that evaluated the muscle function in eight muscle groups (neck flexors, deltoid middle, biceps brachii, wrist extensors, gluteus maximus, gluteus medius, quadriceps, ankle dorsiflexors, with a score that varies from 0 to 80 (15).

The presence of calcinosis was verified, particularly in lumbar spine and total femur.

\section{Laboratory examinations}

Laboratory parameters for bone mineral metabolism such as serum calcium and phosphorus, alkaline phosphatase, 24 hours urinary calcium, were measured in all patients and controls using routine laboratory methods. Serum for the determination of OPG and soluble ligand receptor activator of nuclear factor $\kappa \mathrm{B}$ (SRANKL) was collected from patients and controls after fasting and stored at $-80^{\circ} \mathrm{C}$ for later measurement.

Serum OPG was assayed by ELISA (Biomedica, Vienna, Austria) which uses a monoclonal anti-OPG antibody to capture OPG from serum. Serum levels of uncomplex (free) SRANKL were measured by enzyme immunoassay (Biomedica) according to the manufacturer's instructions (16).

For assessment of laboratory disease and muscle activity, the erythrocyte sedimentation rate (ESR), C-reactive protein levels (CRP) and 
skeletal muscle enzymes: creatine kinase (CK), and aldolase were measured in all patients. Laboratory parameters were considered altered when CRP> 5 ug/dl, ESR > 13 mm, CK> $173 \mathrm{U} / \mathrm{L}$ and aldolase >7.6 U/L.

\section{Dual-energy X-ray absorptiometry (DXA)}

Bone mineral densities were determined by dual energy X-ray absorptiometry using a Hologic QDR 2000 densitometer. Bone mineral density (BMD; g/ $\mathrm{cm}^{2}$ ) and bone area $\left(\mathrm{BA} ; \mathrm{cm}^{2}\right)$ were calculated using the original software of the densitometer. Bone mass was analyzed in lumbar spine (L1-L4), femoral neck, total femur and whole body. In the whole body analysis, the head was excluded in view of the fact that for children under age of $9 \mathrm{yr}$, it contributes to greater variability than age (17).

Moreover, to minimize the confounding effect of skeletal size on DXA measures; volumetric, three-dimensional approximation of bone density, called bone mineral apparent density (BMAD; $\mathrm{g} / \mathrm{cm}^{3}$ ) was calculated. The calculation of volumetric density was obtained by dividing the bone mineral density in spine, femoral neck, total femur or whole body by the square root of spinal, femoral neck, total femur or whole body area $[B M A D=B M D / \sqrt{ } B A$ (where $\mathrm{BA}=$ bone area of the region to be analyzed)] $(10,18,19)$.

Body composition: lean tissue mass and fat mass was also analyzed by DXA using the same densitometer (Hologic QDR 2000) in a pediatric software.

Participants, or guardians for minors, signed a free-informed consent form, and the study was approved by the Ethics Committee of the University Hospital. 


\section{Statistical analysis}

Data are reported as mean \pm S.D. and per cent. Anthropometric and demographic variables, laboratory parameters, BMAD and body composition values were compared between patients and controls using the Student ttest or the Mann-Whitney U-test. The variables Tanner stage $\geq \mathrm{B} 2$, weight $<$ $25^{\text {th }}$ percentile, height $<25^{\text {th }}$ percentile were compared in patients and controls using Fischer's exact test.

In patients with JDM, Person correlation coefficient was used to see the variables correlated to BMAD $(P<0.20)$. Qualitative and quantitative variables correlated to BMAD were submitted to stepwise multiple linear regression analysis using BMAD (femoral neck, total femur and whole body) as a dependent variable. $\mathrm{P}$ values $<0.05$ were considered to be significant.

\section{Results}

Clinical and anthropometric characteristics of patients and controls are shown in Table 1. Mean age of patients and controls was 13.47 and 13.49 years respectively $(P=0.985)$. No difference between patients and controls was observed in anthropometric data for weight and height ( $P>0.05)$, although $35 \%$ of JDM patients were below the $25^{\text {th }}$ percentile of weight compared to $5 \%$ in the control group $(P=0.044)$. Similarly, $60 \%$ of JDM patients and $10 \%$ of control group were below the $25^{\text {th }}$ percentile of height $(P=0.002)$.

Concerning Tanner puberty stage, $90 \%$ of JDM patients and $80 \%$ of control group subjects were puberal, (presenting stages B2P2, B3P3, B4P4, B5P5) $(P=0.661)$. Twelve (60\%) JDM patients and $13(65 \%)$ controls had presented menarche and none of these individuals were amenorrhoeal at study enrolment. No difference in age at menarche was seen between the two study groups (12.09 \pm 1.45 vs. $11.62 \pm 0.96, P=0.234)$ (Table 1$)$.

Calcium ingestion in the diet, associated with oral supplementation was higher in patients with JDM than controls $(1160 \pm 393.57 \mathrm{mg} / \mathrm{day}$ vs. 
$680 \pm 320.94 \mathrm{mg} /$ day, $P<0.001)$. Twelve (60\%) patients with JDM were using calcium supplements, while none of the controls took extra calcium.

The mean disease duration was $46.50 \pm 31.49$ months and six (30\%) patients presented calcinosis (ureter, hip, elbow arm, neck, and knee). No patient had calcinosis in the site that compromise bone mineral density analysis (lumbar and right hip).

The mean disease activity scores were: 3.70 on the DAS, 45.20 on the CMAS and 75.60 on the MMT. Regarding inflammatory laboratory parameters, the mean of ESR was $16.10 \mathrm{~mm} /$ first hour and the CRP was $2.06 \mathrm{mcg} / \mathrm{dl}$. Nine (45\%) JDM patients presented high aldolase and four (20\%) showed high creatine kinase (CK) on study entry.

The cumulative glucocorticoid dose was $17.42 \pm 10.27 \mathrm{~g}$, where the mean GC was $55.88 \pm 10.66 \mathrm{mg} /$ day. Fifty percent of JDM subjects had been using glucocorticoid pulse therapy, and 70\% methotrexate (Table 2).

Serum calcium values trend to be lower in patients compared to controls (9.60 \pm 0.27 vs. $9.80 \pm 0.43 \mathrm{mg} / \mathrm{dl}, P=0.050)$, whereas no difference was observed in phosphorus, alkaline phosphatase, 24 hours calciuria, OPG and sRANKL between study groups ( $\mathrm{P}>0.05$ ) (Table 3).

BMAD was reduced in JDM patients versus controls in femoral neck (0.302 \pm 0.059 vs. $\left.0.373 \pm 0.049 \mathrm{~g} / \mathrm{cm}^{3}, P<0.001\right)$, total femur (0.128 \pm 0.022 Vs. $0.155 \pm 0.019 \mathrm{~g} / \mathrm{cm}^{3}, P<0.001$ ) and whole body without head $\left(0.657 \pm 0.135 v s .0 .776 \pm 0.120 \mathrm{~g} / \mathrm{cm}^{3}, P=0.005\right)$. Differently, no difference was observed in BMAD of lumbar spine $(0.1115 \pm 0.045$ vs. $0.117 \pm 0.016$ $\mathrm{g} / \mathrm{cm}^{3}, P=0.809$ ) (Table 4).

Body composition analysis evidenced lower lean body mass (24.04 \pm 7.38 vs. $30.08 \pm 7.66 \mathrm{~kg}, \mathrm{P}=0.015)$ and lower bone mineral content (1.134 \pm 0.512 vs. $1.500 \pm 0.502 \mathrm{~kg}, \mathrm{P}=0.028$ ) in patients than in controls. However, there was no difference in terms of fat body mass (16.13 \pm 7.19 kg vs. $14.82 \pm 7.17 \mathrm{~kg}, P=0.565$ ) (Table 4).

It should be highlighted that multiple regression analysis of JDM patients using BMAD (femoral neck, total femur and whole body without 
head) as dependent variable; and all parameters that correlated to BMAD by Pearson analysis $(P<0.20)$ as independent variables, revealed that BMAD was associated with lean body mass $(P<0.01)$ and GC pulse therapy use $(P<0.05)$, in femoral neck and total femur (Table 5). No association was observed between BMAD in the whole body and other dependent variables.

\section{Discussion}

The present study has shown lower volumetric bone mineral density in patients with juvenile dermatomyositis compared to healthy controls compromising femoral neck, total femur and whole body.

The few studies in the literature which have also analyzed bone mass in JDM children, showing reduced bone mineral density mainly in the lumbar spine in these children and adolescents (20-22).

Differently to the present study, these authors (20-22) had analyzed areal bone density instead of volumetric bone density and consequently the scan DXA results were not correct by the bone size of these children.

DXA provides only two dimensional measurements of bone mineral content and bone area for the three-dimensional bone. Thus, BMD is not a measure of volumetric density $\left(\mathrm{g} / \mathrm{cm}^{3}\right)$ because it provides no information about bone depth. Bones of larger width and height are also thicker. In this manner, BMD of bones with identical volumetric BMD but varying size will differ substantially in areal BMD. Smaller bones will have a lower areal BMD than larger bones because bone thickness is not factored into DXA results. Children who are small for their age will have a lower areal BMD than the same-age peers, even if their volumetric BMD is identical $(18,19)$.

Because of the confounding by bone size, the present study calculated the bone mineral apparent density as an estimation of volumetric density, which reduces the effect of bone size on bone mass $(10,19,23,24)$, since a higher percent of JDM patients were in the percentile lower $25^{\text {th }}$ of height and weight compare to age-matched controls. 
Different from former literature studies, lumbar bone density in our JDM patients did not differ to healthy controls (20-22). The most likely explanation of these findings may be related to volumetric BMD analysis in our study, compare to areal BMD evaluated by the other investigators (2022).

In our JDM patients, we found a tendency of lower serum calcium values than in healthy controls, although levels were within normal limits. These findings may be associated to lower calcium absorption secondary to use of medicines such as GC, or to lower vitamin D synthesis due to lower exposure to sunlight, given that calcium ingestion was actually higher in the JDM patients.

Adequate calcium and vitamin $\mathrm{D}$ ingestion during childhood and adolescence is fundamental for good skeletal mineralization. Johnston et al. demonstrated that calcium supplementation facilitates rates of BMD increase in normal pre-pubertal children (25). Furthermore, Warady et al. found a significant BMD increase in the spines of children with rheumatic diseases receiving at least $1 \mathrm{~g}$ of calcium and $400 \mathrm{UI}$ of vitamin D (26). In contrast, Reed et al. supplemented JDM children's diets with $25(\mathrm{OH})$ of vitamin D over a 1-year period yet observed no increase in BMD at end point (27).

Osteoprotegerin, RANK and RANKL, members of the tumor necrosis factor have been implicated in bone mineral metabolism in inflammatory chronic diseases (28). RANKL interacts with its receptor-RANK on the surface of premature osteoclasts inducing osteoclast formation, activation, and survival of these cells. OPG functions as a soluble decoy receptor for RANKL, and competes with RANK for RANKL binding. Consequently OPG is an effective inhibitor of osteoclast maturation and osteoclast activation in vivo and in vitro $(28,29)$.

In the present study, no difference was observed between patients and healthy age- matched controls related to OPG and RANKL sera levels. Inflammatory cytokines associated with muscle damage (such as TNF- $\alpha$, IL1) $(30,31)$, can increase OPG production by osteoblast/stromal and 
endothelial cells (32) and counterbalance the glucocorticoid action, that decrease the production of OPG and increase the expression of RANKL in skeletal and vascular systems.

Controversy in the literature remains concerning disease activity and glucocorticoid use, and BMD in juvenile rheumatic disease. Stewart et a.l found osteopenia in JDM patients, even when the disease was inactive and in patients who had not used corticoid for between three to eight years (20). These authors concluded that owing to the use of high corticoid doses, it was common place to find low density bone mineral in JDM, where greater recovery periods are required for bone mass to normalize. Unlike JDM patients, those with a history of juvenile rheumatoid arthritis have been shown to reach a normal bone mass peak (at the spine region) in adult life, even though the majority of such cases had active disease at puberty (33). Therefore, JDM patients display a greater tendency to develop osteoporosis in adult life as a result of low bone reserves acquired during and adolescence and early adulthood (20).

Castro et al. (22) upon measuring bone mineral density in ten girls with JDM also evidenced a significant reduction in bone mineral density in the lumbar spine in these patients compared to controls, and found no correlation between bone mineral density and disease activity, disease duration or corticoid use.

Alsufyani et al. analyzing bone mineral density in children with juvenile dermatomyositis, juvenile systemic lupus erythematosus and systemic vasculitis showed reduced BMD associated to cumulative GC dose, but no correlation with disease activity (21).

In the present study no correlation was found between: disease activity score, muscle strength score, GC cumulative dose, and BMAD in JDM patients. Differently, an association between glucocorticoid pulse therapy use and BMAD was observed in our patients. Similarly, Haugeberg et al examined 38 patients with various rheumatic diseases that requiring intravenous methylprednisolone pulse treatment for a median period of 6 months, 
demonstrated an important decreased of bone mass mainly in femoral neck $(-2,2 \%)$ and total hip $(-1,1 \%)$. Surprisingly, these authors found no significant difference in BMD loss between users and non-users of oral prednisone treatment (34).

Another interesting finding in our work was the association of BMAD with lean mass in JDM patients.

Several studies have shown body mass to be the best predictor of bone mass in healthy children $(35,36)$, as well as in children with chronic diseases $(22,37)$, and that low weight represents an important risk factor for osteoporosis, besides vertebral and hip fractures $(38,39)$. Nevertheless, there is conjecture over what mechanism allows the two components of body weight, lean mass and fat mass, to determine bone mineral density.

In fact, the present study, the first of its kind to analyze body composition in juvenile dermatomyositis patients, has shown using linear regression analysis that low lean mass is an independent factor associated with the low bone mineral density found in femoral neck, total femur in our JDM child sample.

In-line with our findings, Lien et al. (5) in a prospective longitudinal study comparing 100 children with juvenile idiopathic arthritis with 100 healthy children, found a low gain of bone mineral content to be associated with a low gain in lean mass. These authors concluded that this altered body composition may possibly have been linked to the chronic inflammatory process and reduced physical activity.

A number of other studies have shown that besides the chronic inflammatory process, the use of glucocorticoid may be responsible for low bone mineral density and alteration in body composition, leading to a reduction of lean mass, with or without an increase in fat mass $(9,40)$. Glucocorticoid inhibits protein synthesis and stimulates protein breakdown in skeletal muscle, resulting in protein catabolism and reduced muscle mass (41). 
In our JDM patients, lean mass and GC pulse therapy use, were independent factors associated to BMAD in hip site concluding that perhaps the chronic muscle inflammatory process along with the resulting immobilization and high doses of steroids were more important factors in reduced bone and muscle mass in these patients.

Thus, the present work analyzing volumetric bone mineral density (BMAD) that minimized the confounding effects in bone size in JDM patients, showed that low lean mass and GC pulse therapy use were the main factors related to low bone mass in children, highlighting the need for more focused muscle therapy, and a careful use of GC in order to prevent bone hip loss in these patients. 


\section{References:}

1. Cassidy JT. Osteopenia and osteoporosis in children. Clin Exp Rheumatol 1999;17:245-2550.

2. Perez MD, Abrams SA, Koenning G, Stuff JE, O`Brien KO, Ellis KJ. Mineral metabolism in children with dermatomyositis. J Rheumatol 1994;21:2364-9.

3. Pepmueller PH, Cassidy JT, Allen SH, Hillman LS. Bone mineralization and bone mineral metabolism in children with juvenile rheumatoid arthritis. Arthritis Rheum 1996;39:746-57.

4. Pereira RMR, Corrente JE, Chahade W, Yoshinari NH. Evaluation by dual X-ray absorptiometry (DXA) of bone mineral density in children with juvenile chronic arthritis. Clin Exp Rheumatol 1998;16:495-501.

5. Lien G, Selvaag AM, Flato B et al. A two-year prospective controlled study of bone mass and bone turnover in children with early juvenile idiopathic arthritis. Arthritis Rheum 2005;52:883-40.

6. Khan AA, Bachrach L, Brown JP, et al. Standards and guidelines for performing central dual-energy X-ray absorptiometry in premenopausal women, men, and children. J Clin Densitom 2004;51-63.

7. Genant HK, Engelke $K$, Fuerst $T$, et al. Noninvasive Assessment of bone mineral and structure:state of the art. J Bone Miner Res 1996; 11:707-30.

8. Brambilla $\mathrm{P}$, Rolland-Cachera $\mathrm{M}-\mathrm{F}$, Testolin $\mathrm{C}$ et al. Lean mass of children in various nutritional states. Comparison between dual-energy 
X-ray absorptiometry and anthropometry. Ann N Y Acad Sci 2000;904:433-6.

9. Kipen Y, Strauss JG, Morand EF. Body composition in systemic lupus erythematosus. Br J Rheumatol 1998;37:514-19.

10. Carter DR, Bouxsein ML, Marcus R. New approaches for interpreting projected bone densitometry data. J Bone Miner Res 1992;7:137-145.

11. Bohan A, Peter JB. Polymyositis and dermatomyositis. N Engl J Med $1975 ; 292: 344-7$.

12. Tanner JM. Growth at adolescence. 2nd ed. Oxford: Blackwell Scientific Publications; 1962.

13. Bode RK, Klein-Gitelman MS, Miller ML, Lechman TS, Pachman LM. Disease activity scores for children with juvenile dermatomyositis: reliability and validity evidence. Arthritis Rheum 2003;49:7-15.

14. Lovell DJ, Lindslev CB, Rennebohm RM, et al. Development of validated disease activity and damage indices for the juvenile idiopathic inflammatory myopathies. II. The Childhood Myositis Assessment Scale (CMAS): a quantitative tool for the evaluation of muscle function. The Juvenile Dermatomyositis Disease Activity Collaborative Study Group. Arthritis Rheum 1999;42:2213-9.

15. Florence JM, Pandya S, King WM et al. Intrarater reliability of manual muscle test (Medical Research Council scale) grades in Duchenne's muscular dystrophy. Phys Ther 1992;72:115-22. 
16. Bezerra MC, Calomeni GD, Caparbo VF, Gebrim ES, Rocha MS, Pereira RMR. Low bone density and low serum levels of soluble RANK ligand are associated with severe arterial calcification in patients with Takayasu arteritis. Rheumatology 2005;44:1503-06.

17. Taylor A, Konrad PT, Norman ME, Harcke HT. Total body bone mineral density in young children: influence of head bone mineral density. J Bone Miner Res 1997;12:652-5.

18. Crabtree NJ, Leonard MB, Zemel BS. Dual-Energy X-Ray Absorptiometry. In: Sawyer AJ, Bachrach LK, Fung EB, eds. Bone Densitometry in Growing Patients: Guidelines for Clinical Practice. Totowa, New Jersey: Humana Press Inc, 2007;41-57.

19. Cvijetic $S$, Korsic M. Apparent bone mineral density estimated from DXA in healthy men and women. Osteoporos int 2004;15:295-300.

20. Stewart WA, Acott PD, Salisbury SR, Lang BA. Bone Mineral Density in Juvenile Dermatomyositis. Arthritis Rheum 2003;48:2294-98.

21. Alsufyani KA, Ortiz-Alvarez O, Cabral DA, et al. Bone mineral density in children and adolescents with systemic lupus erythematosus, juvenile dermatomyositis and systemic vasculitis: relationship to disease duration, cumulative corticosteroid dose, calcium intake and exercise. J Rheumatol 2005;32:729-33.

22. Castro TCM, Terreri MTRA, Szejnfeld VL, Len C, Fonseca ASM, Hilário MOE. Bone mineral density of Brazilian girls with juvenile dermatomyositis. Braz J Med Biol Res 2005;38:309-13. 
23. Bachrach LK, Hastie T, Wang MC, Narasimhan B, Marcus R. Bone mineral acquisition in heathy Asian, Hispanic, Black, and Caucasian youth: A longitudinal study. J Clin Endocrinol Metab 1999; $84: 4702-4712$.

24. Wang MC, Aguirre M, Bhudhikanok GS, et al. Bone mass and hip axis length in healthy Asian, black, Hispanic, and white American youths. J Bone Miner Res 1997;12:1922-1935.

25. Johnston CC Jr, Miller JZ, Slemenda CW, et al. Calcium suplementation and increases in bone mineral density in children. $\mathrm{N}$ Engl J Med $1992 ; 327: 82-7$.

26. Warady BD, Lindsley CB, Robinson FG, Lukert BP. Effects of nutritional supplementation on bone mineral status of children with rheumatic diseases receiving corticosteroid therapy. J Rheumatol 1994;21:530-5.

27. Reed A, Haugen M, Pachman LM, Langman CB. 25-hydroxyvitamin D therapy in children with active juvenile rheumatoid arthritis: short-term effects on serum osteocalcin levels and bone mineral density. J Pediatr 1991;119:657-60.

28. Bezerra MC, Carvalho JF, Prokopowitsch AS, Pereira RMR. RANK, RANKL and osteoprotegerina in arthritis bone loss. Braz J Med Biol Res 2005; 38:161-70.

29. Kong YY, Boyle WJ, Penninger JM. Osteoprotegerin ligand: a regulator of immune responses and bone physiology. Immunol Today 2000;21:495-502. 
30. Mackiewicz Z, Hukkanen M, Povilenaite D, et al. Dual effects of caspase-1, interleukin-1 beta, tumour necrosis factor-alpha and nerve growth factor receptor in inflammatory myopathies. Clin Exp Rheumatol 2003;21:41-8.

31. Salomonsson S, Lundberg IE. Cytokines in idiopathic inflammatory myopathies. Autoimmunity 2006;39:117-90.

32. Hofbauer LC, Schoppet M. Clinical implications of osteoprotegerin/ RANKL/RANK system for bone and vascular diseases. JAMA 2004:292:490-5

33. Haugen $M$, Lien $G$, Flato $B$, et al. Young adults with juvenile arthritis in remission attain normal peak bone mass at lumbar spine and forearm. Arthritis Rheum 2000;43:1504-10.

34. Haugeberg G, Griffiths B, Sokoll KB, Emery P. Bone loss in patients treated with pulses of methylprednisolone is not negligible: a short term prospective observational study. Ann Rheum Dis 2004;63:940-4.

35. Bonjour J P, Theintz G, Buchs B, Slosman D \& Rizzoli R. Critical years and stages of puberty for spinal and femoral bone mass accumulation during adolescence. J Clin Endocrinol Metab 1991;73:555-63.

36. Theintz G, Buchs B, Rizzoli R, et al. Longitudinal monitoring of bone mass accumulation in healthy adolescents: evidence for a marked reduction after 16 years of age at the levels of lumbar spine and femoral neck in female subjects. J Clin Endocrinol Metab 1992;75:1060-65. 
37. Kotaniemi A, Savolainen A, Kröger $H$, Kautiainen $H$, Isomaki H. Weightbearing physical activity, calcium intake, systemic glucocorticoid, chronic inflammation and body constitution as determinants of lumbar and femoral bone mineral in juvenile chronic arthritis. Scand J Rheumatol 1999;28:19-26.

38. Reid IR. Relationships among body mass, its components, and bone. Bone 2002;31:547-55.

39. Lim S, Joung $H$, Shin $C S$, et al. Body composition changes with age have gender-specific impacts on bone mineral density. Bone 2004;35:792-8.

40. Mul D, Suijlekom-Smit van LWA, Cate ten R, Bekkering WP, Muinck keizer-Schrama de SM. Bone mineral density and body composition and influencing factors in children with rheumatic diseases treated with corticosteroids. J Pediat Endocrinol Metab 2002;15:187-92.

41. Rebuffe-Scrive M, Krotkiewski M, Elfverson J, Bjorntorp P. Muscle and adipose tissue morphology and metabolism in Cushing's syndrome. J Clin Endocrinol Metab 1998;67:1122-28. 
Table 1 - Demographic and anthropometric characteristics, calcium ingestion, in patients with Juvenile Dermatomyositis (JDM) and controls. Data expressed in mean and standard deviation, or percentage

\begin{tabular}{lccc}
\hline & $\begin{array}{c}\text { JDM } \\
(\mathrm{n}=20)\end{array}$ & $\begin{array}{c}\text { Control } \\
(\mathrm{n}=20)\end{array}$ & $P$ \\
\hline Age (years) & $13.47 \pm 4.24$ & $13.49 \pm 4.12$ & 0.985 \\
Weight $(\mathrm{Kg})$ & $42.62 \pm 13.30$ & $48.05 \pm 14.44$ & 0.224 \\
Weight $<25^{\text {th }}$ percentile, $\mathrm{n}(\%)$ & $7(35)$ & $1(5)$ & $\mathbf{0 . 0 4 4}$ \\
Height $(\mathrm{cm})$ & $142.70 \pm 16.92$ & $149.90 \pm 14.27$ & 0.154 \\
Height $<25^{\text {th }}$ percentile, $\mathrm{n}(\%)$ & $12(60)$ & $2(10)$ & $\mathbf{0 . 0 0 2}$ \\
Tanner Stage $\geq$ B2, $\mathrm{n}(\%)$ & $18(90)$ & $16(80)$ & 0.661 \\
Menarche age (years)* & $12.09 \pm 1.45$ & $11.62 \pm 0.96$ & 0.234 \\
Calcium ingestion (mg/day) & $1160 \pm 393.57$ & $680 \pm 320.94$ & $\mathbf{0 . 0 0 1}$ \\
\hline * Only 12 JDM and 13 controls had already presented menarche.
\end{tabular}

* Only 12 JDM and 13 controls had already presented menarche. 
Table 2 - Clinical characteristics, disease activity and muscle strength scores, inflammatory and muscle laboratory parameters, and treatment in patients with Juvenile Dermatomyositis (JDM) and controls. Data expressed in mean and standard deviation, or percentage

\begin{tabular}{lc}
\hline & JDM \\
& $(\mathrm{n}=20)$ \\
\hline Disease duration (months) & $46.50 \pm 31.49$ \\
Calcinosis, $\mathrm{n}(\%)$ & $6(30)$ \\
DAS (score, 0-20) & $3.70 \pm 4.90$ \\
CMAS (score, 0-53) & $45.20 \pm 10.32$ \\
MMT (score, 0-80) & $75.60 \pm 5.95$ \\
ESR (mm/first hour) & $16.10 \pm 7.20$ \\
CRP (mcg/dl) & $2.06 \pm 2.02$ \\
High CK, $\mathrm{n}(\%)$ & $4(20)$ \\
High aldolase, $\mathrm{n}(\%)$ & $9(45)$ \\
Cumulative GC dose, $\mathrm{g}$ & $17.42 \pm 10.27$ \\
GC pulse therapy, $\mathrm{n}(\%)$ & $10(50)$ \\
Methotrexate use, $\mathrm{n}(\%)$ & $14(70)$ \\
\hline
\end{tabular}

DAS- disease activity score, CMAS-childhood myositis assessment scale, MMT- manual muscle testing, ESR- erythrocyte sedimentation rate, CRP- C reactive protein, CK- creatine kinase, GC- glucocorticoid. 
Table 3 - Laboratorial parameters of bone mineral metabolism: calcium, phosphorus, alkaline phosphatase, 24 hour calciuria, Osteoprotegerin (OPG), SRANKL (soluble ligand receptor activator of nuclear factor $\kappa \mathrm{B}$ ), in patients with Juvenile Dermatomyositis (JDM) and controls. Data expressed in mean and standard deviation

\begin{tabular}{lccc}
\hline & $\begin{array}{c}\text { JDM } \\
(\mathrm{n}=20)\end{array}$ & $\begin{array}{c}\text { Control } \\
(\mathrm{n}=20)\end{array}$ & $P$ \\
\hline Serum calcium $(\mathrm{mg} / \mathrm{dl})$ & $9.60 \pm 0.27$ & $9.80 \pm 0.43$ & $\mathbf{0 . 0 5 0}$ \\
Phosphorus $(\mathrm{mg} / \mathrm{dl})$ & $4.60 \pm 0.69$ & $4.48 \pm 0.71$ & 0.591 \\
Alkaline phosphatase (U/L) & $117.11 \pm 59.52$ & $152.55 \pm 85.57$ & 0.137 \\
24h Calciuria (mg/kg/24h) & $2.15 \pm 1.15$ & $2.69 \pm 1.31$ & 0.215 \\
OPG (pg/ml) & $38.19 \pm 26.71$ & $29.31 \pm 32.92$ & 0.355 \\
sRANKL $(\mathrm{pg} / \mathrm{ml})$ & $4.72 \pm 3.59$ & $4.57 \pm 4.01$ & 0.899 \\
OPG/sRANKL & $11.57 \pm 12.87$ & $11.69 \pm 16.50$ & 0.979 \\
\hline
\end{tabular}


Table 4 - Bone mineral apparent density (BMAD) in lumbar spine (L1-L4), femoral neck, total femur, whole body, and body composition (lean mass and fat mass) in patients with juvenile dermatomyositis (JDM) and controls. Data expressed in mean and standard deviation

\begin{tabular}{lccc}
\hline & $\begin{array}{c}\text { JDM } \\
(\mathrm{n}=20)\end{array}$ & $\begin{array}{c}\text { Control } \\
(\mathrm{n}=20)\end{array}$ & $P$ \\
\hline BMAD - L1-L4 $\left(\mathrm{g} / \mathrm{cm}^{3}\right)$ & $0.115 \pm 0.045$ & $0.117 \pm 0.016$ & 0.809 \\
BMAD - femoral neck $\left(\mathrm{g} / \mathrm{cm}^{3}\right)$ & $0.302 \pm 0.059$ & $0.373 \pm 0.049$ & $<\mathbf{0 . 0 0 1}$ \\
BMAD - total femur $\left(\mathrm{g} / \mathrm{cm}^{3}\right)$ & $0.128 \pm 0.022$ & $0.155 \pm 0.019$ & $<\mathbf{0 . 0 0 1}$ \\
BMAD - whole body $\left(\mathrm{g} / \mathrm{cm}^{3}\right)$ & $0.657 \pm 0.135$ & $0.776 \pm 0.120$ & $\mathbf{0 . 0 0 5}$ \\
Lean mass $(\mathrm{Kg})$ & $24.04 \pm 7.38$ & $30.08 \pm 7.66$ & $\mathbf{0 . 0 1 5}$ \\
Fat mass $(\mathrm{Kg})$ & $16.13 \pm 7.19$ & $14.82 \pm 7.17$ & 0.565 \\
\hline
\end{tabular}


Table 5- Multiple linear regression analysis using: femoral neck BMAD and total femur BMAD as dependent variables.

$\beta$ Coeficient Standard error $\quad P$

\begin{tabular}{lcccc}
\hline BMAD femoral & Constant & 0,19 & 0,031 & $<\mathbf{0 , 0 0 1}$ \\
neck $\left(\mathrm{g} / \mathrm{cm}^{3}\right)$ & Lean mass $(\mathrm{Kg})$ & 0,006 & 0,001 & $<\mathbf{0 , 0 0 1}$ \\
& GC pulse therapy & $-0,043$ & 0,017 & $\mathbf{0 , 0 2 4}$ \\
\hline \multirow{2}{*}{ BMAD total } & Constant & 0,102 & 0,013 & $<\mathbf{0 , 0 0 1}$ \\
femur $\left(\mathrm{g} / \mathrm{cm}^{3}\right)$ & Lean mass $(\mathrm{Kg})$ & 0,002 & 0,000 & $\mathbf{0 , 0 0 4}$ \\
& GC pulse therapy & $-0,022$ & 0,007 & $\mathbf{0 , 0 0 5}$ \\
\hline
\end{tabular}




\title{
Anexo 2. Termo de Consentimento Livre e Esclarecido
}

\author{
HOSPITAL DAS CLÍNICAS \\ DA
}

FACULDADE DE MEDICINA DA UNIVERSIDADE DE SÃO PAULO

TERMO DE CONSENTIMENTO LIVRE E ESCLARECIDO

(Instruções para preenchimento no verso)

\section{I - DADOS DE IDENTIFICAÇÃO DO SUJEITO DA PESQUISA OU RESPONSÁVEL LEGAL}

1. NOME DO PACIENTE .

DOCUMENTO DE IDENTIDADE No : SEXO : $M \quad F$

DATA NASCIMENTO $. / \ldots \ldots . . . . . . .$. APTO:

ENDEREÇO $\mathrm{N}^{\mathrm{o}}$ CIDADE

BAIRRO:

CEP:...... TELEFONE: DDD )

2.RESPONSÁVEL LEGAL

NATUREZA (grau de parentesco, tutor, curador etc.)

DOCUMENTO DE IDENTIDADE $N^{\circ}$ :

SEXO : $M \quad F$

DATA NASCIMENTO: .......................

ENDEREÇO $\mathrm{N}^{\mathrm{O}}$ APTO:

BAIRRO: CIDADE

CEP TELEFONE: DDD ( ).

\section{II - DADOS SOBRE A PESQUISA CIENTÍFICA}

1.TÍTULO DO PROTOCOLO DE PESQUISA:

AVALIAÇÃO DO METABOLISMO ÓSSEO E COMPOSIÇÃO CORPORAL EM PACIENTES COM DERMATOMIOSITE JUVENIL. 
2. PESQUISADOR: ROSABRAULIA ACCIOLY SANTIAGO CARGO/FUNÇÃO: PÓS GRADUANDA INSCRIÇÃO CONSELHO REGIONAL No 95208 UNIDADE DO HCFMUSP: LIM-17 ( REUMATOLOGIA)

3. AVALIAÇÃO DO RISCO DA PESQUISA:

$\begin{array}{lll}\text { SEM RISCO } & \text { RISCO MÍNIMO } & \text { RISCO MÉDIO } \\ \text { RISCO BAIXO } & \text { RISCO MAIOR }\end{array}$

(probabilidade de que o indivíduo sofra algum dano como consequência imediata ou tardia do estudo)

4. DURAÇÃO DA PESQUISA : 4 ANOS. 


\section{III - REGISTRO DAS EXPLICAÇÕES DO PESQUISADOR AO PACIENTE OU SEU REPRESENTANTE LEGAL SOBRE A PESQUISA, CONSIGNANDO:}

1.justificativa e os objetivos da pesquisa; 2.procedimentos que serão utilizados e propósitos, incluindo a identificação dos procedimentos que são experimentais; 3.desconfortos e riscos esperados; 4.benefícios que poderão ser obtidos; 5.procedimentos alternativos que possam ser vantajosos para o indivíduo.

O reumatismo ou as medicações usadas para o tratamento da sua doença (dermatomiosite juvenil) podem fazer com que o seu osso fique mais fraco, podendo quebrar-se com facilidade. O objetivo desde estudo será avaliar através da densitometria óssea (aparelho para medir a quantidade de osso), do Rx de coluna(para ver fraturas) e através de exames de sangue (específicos para o osso) como está o osso do seu corpo. Através destes exames iremos diagnosticar se você tem ou não problema ósseo e deste modo tratar você mais adequadamente. Não há nenhum risco ou desconforto na realização da densitometria óssea e na coleta de sangue somente o desconforto da picada. Caso você não queira participar do estudo, continuirá sendo acompanhado no ambulatório de Reumatologia.

\section{IV - ESCLARECIMENTOS DADOS PELO PESQUISADOR SOBRE GARANTIAS DO SUJEITO DA PESQUISA:}

1. acesso, a qualquer tempo, às informações sobre procedimentos, riscos e benefícios relacionados à pesquisa, inclusive para dirimir eventuais dúvidas.

2. liberdade de retirar seu consentimento a qualquer momento e de deixar de participar do estudo, sem que isto traga prejuízo à continuidade da assistência.

3. salvaguarda da confidencialidade, sigilo e privacidade.

4. disponibilidade de assistência no HCFMUSP, por eventuais danos à saúde, decorrentes da pesquisa.

5. viabilidade de indenização por eventuais danos à saúde decorrentes da pesquisa.

O paciente ou responsável terá acesso para questões sobre seus direitos como indivíduo do estudo, entrando em contato com a Comissão de Ética do Hospital das Clínicas, no telefone 3069-6442. Para qualquer pergunta sobre o estudo, entrar em contacto com o medico do estudo Dra Rosa Maria R. Pereira no telefone 3066-7213. A participação do paciente neste estudo é voluntária, podendo escolher não fazer parte deste estudo. Caso o paciente concorde em participar deste estudo, isto será mantido em sigilo. Este estudo não envolve danos à saúde do paciente. 
V. INFORMAÇÕES DE NOMES, ENDEREÇOS E TELEFONES DOS RESPONSÁVEIS PELO ACOMPANHAMENTO DA PESQUISA, PARA CONTATO EM CASO DE INTERCORRÊNCIAS CLÍNICAS E REAÇÕES ADVERSAS.

Dra Rosa Maria Rodrigues Pereira - Faculdade de Medicina da USP - $3^{\circ}$ andar Reumatologfia sala 3107

VI. OBSERVAÇÕES COMPLEMENTARES:

\section{VII - CONSENTIMENTO PÓS-ESCLARECIDO}

Declaro que, após convenientemente esclarecido pelo pesquisador e ter entendido o que me foi explicado, consinto em participar do presente Protocolo de Pesquisa

São Paulo,

de

de 2004 


\section{Anexo 3. Escore de Atividade de Doença (DAS)}

\section{DISEASE ACTIVITY SCORE (DAS)}

\begin{tabular}{|c|c|}
\hline 1. ESTADO FUNCIONAL & \\
\hline Função normal & $\mathbf{0}$ \\
\hline Limitação leve & $\mathbf{1}$ \\
\hline Limitação moderada & $\mathbf{2}$ \\
\hline Limitação grave & $\mathbf{3}$ \\
\hline
\end{tabular}

\begin{tabular}{|c|c|c|}
\hline \multicolumn{1}{|c|}{ 2.FRAQUEZA MUSCULAR } & NÃO & SIM \\
\hline Fraqueza da musculatura flexora do pescoço & $\mathbf{0}$ & $\mathbf{1}$ \\
\hline Fraqueza da musculatura abdominal & $\mathbf{0}$ & $\mathbf{1}$ \\
\hline Fraqueza da musculatura proximal superior & $\mathbf{0}$ & $\mathbf{1}$ \\
\hline Fraqueza da musculatura proximal inferior & $\mathbf{0}$ & $\mathbf{1}$ \\
\hline Sinal de Gowers & $\mathbf{0}$ & $\mathbf{1}$ \\
\hline Andar anormal & $\mathbf{0}$ & $\mathbf{1}$ \\
\hline Dificuldade de engolir & $\mathbf{0}$ & $\mathbf{1}$ \\
\hline Voz anasalada & $\mathbf{0}$ & $\mathbf{1}$ \\
\hline
\end{tabular}

\begin{tabular}{|c|c|}
\hline 3.TIPO DE ENVOLVIMENTO CUTÂNEO & \\
\hline Ausente ou resolvido completamente & $\mathbf{0}$ \\
\hline Apenas atrofia (incluindo pápulas de Gottrons) & $\mathbf{1}$ \\
\hline Eritema leve & $\mathbf{2}$ \\
\hline Eritema moderado & $\mathbf{3}$ \\
\hline Eritema grave & $\mathbf{4}$ \\
\hline
\end{tabular}

\begin{tabular}{|c|c|}
\hline 4. DISTRIBUIÇÃO DO ENVOLVIMENTO CUTÂNEO & \\
\hline Nenhum & $\mathbf{0}$ \\
\hline Focal (incluindo pele ao redor das articulações) & $\mathbf{1}$ \\
\hline Difuso(incluindo superfícies extensoras dos braços) & $\mathbf{2}$ \\
\hline Generalizado (incluindo tronco) & $\mathbf{3}$ \\
\hline
\end{tabular}

\begin{tabular}{|c|c|c|}
\hline 5.VASCULITE & Ausente & Presente \\
\hline Eritema palpebral & $\mathbf{0}$ & $\mathbf{1}$ \\
\hline Dilatação vascular palpebral & $\mathbf{0}$ & $\mathbf{1}$ \\
\hline Trombose palpebral & $\mathbf{0}$ & $\mathbf{1}$ \\
\hline Eritema periungueal & $\mathbf{0}$ & $\mathbf{1}$ \\
\hline Telangiectasia ungueal & $\mathbf{0}$ & $\mathbf{1}$ \\
\hline Dilatação em palato & $\mathbf{0}$ & $\mathbf{1}$ \\
\hline Outros & $\mathbf{0}$ & $\mathbf{1}$ \\
\hline
\end{tabular}

\begin{tabular}{|c|c|}
\hline 6. PÁPULAS DE GOTTRONS & \\
\hline Ausente & $\mathbf{0}$ \\
\hline Leve & $\mathbf{1}$ \\
\hline Moderado & $\mathbf{2}$ \\
\hline Grave & $\mathbf{3}$ \\
\hline
\end{tabular}

A SOMA DOS VALORES OBTIDOS VARIA DE 0 (VALOR MÍNIMO) E 20 (VALOR MÁXIMO). 


\title{
Anexo 4. Escala de Avaliação da Miosite na I nfância (CMAS)
}

\author{
CHILDHOOD MYOSITIS ASSESSMENT SCALE (CMAS)
}

\author{
1. Elevação da cabeça (flexão do pescoço) \\ $0=$ Incapaz \\ $1=1-9$ segundos \\ $2=10-29$ segundos \\ $3=30-59$ segundos \\ $4=10-119$ segundos \\ $5=\geq 2$ minutos \\ \# segundos \\ 2. Elevação das Pernas/Alcançar e tocar Objeto \\ $0=$ Incapaz de elevar a perna acima da mesa de exame \\ $1=$ Capaz de elevar a perna, mas não consegue tocar objeto (mão do examinador) \\ $2=$ capaz de levar a perna e tocar objeto (mão do examinador)
}

3. Duração da manobra de pernas elevadas e estendidas

$0=$ Incapaz

$1=1-9$ segundos

$2=10-29$ segundos

$3=30-59$ segundos

4.'Virar de bruços' Do decúbito dorsal ao ventral.

$0=$ Incapaz. Tem dificuldade ate para virar de lado, capaz de liberar os braços do tronco parcialmente ou incapaz de liberar o braço.

1= Vira-se de lado com relativa facilidade, mas não consegue liberar os braços do tronco e não consegue assumir o decúbito ventral completo.

$2=$ Vira-se de lado facilmente, tem alguma dificuldade para liberar os braços do tronco, mas libera-os completamente e assume o decúbito ventral.

$3=$ Vira-se de bruços facilmente, libera os braços sem nenhuma dificuldade.

\section{5. "Abdominais" / Flexão do tronco}

Mãos apoiadas nas coxas, com contrabalanço

Mãos cruzadas no peito, com contrabalanço

Mãos na nuca , com contrabalanço

Mãos apoiadas nas coxas, sem contrabalanço

Mãos cruzadas no peito, sem contrabalanço

Mãos na nuca , sem contrabalanço

\section{6.'Sentar-se’ - Do decúbito dorsal à posição sentada}

$0=$ Incapaz de sentar-se sem ajuda

1= Muita dificuldade. Muito lento, esforça-se e quase não consegue

2= Alguma dificuldade. Capaz de fazer, mas lentamente e com certo esforço.

$3=$ Nenhuma dificuldade

\section{Elevação dos braços estendidos}

$0=$ Não consegue elevar os punhos ate o nível da articulação acromio-clavicular (AC)

$1=$ Consegue elevar os punhos acima da articulação AC, mas não acima do topo da cabeça

$2=$ Consegue elevar os punhos acima do topo da cabeça, mas não consegue elevar os braços com extensão completa dos cotovelos

3= Eleva os braços completamente estendidos acima da cabeça

\section{Elevação dos braços/ Duração}

$0=$ Incapaz

$1=1-9$ segundos

$2=10-29$ segundos

$3=30-59$ segundos

$4=\geq 60$ segundos 
9.Sentar-se no chão. (Partindo da posição ortostatica, sentar-se no chão)

$0=$ Incapaz. Temeroso ate de tentar, mesmo com o apoio de uma cadeira (A criança tem medo de cair e machucar-se durante a manobra)

1= Muita dificuldade. Consegue, mas precisa de apoio da cadeira durante a descida. Incapaz , recusa-se a fazer o exercício sem o apoio de uma cadeira.

2= Alguma dificuldade. Consegue, estando em pé abaixar-se e sentar no chão, mas tem alguma dificuldade na descida. Pode fazer a 'manobra de Gower'. Abaixa-se lentamente ou apreensivamente, pode não ter controle completo do equilíbrio para assumir aposição sentada.

$3=$ Nenhuma dificuldade. Não requer nenhuma manobra compensatória.

\section{Posição de quatro I "Engatinhar"}

$0=$ Incapaz de partir do decúbito ventral para a posição de quatro

1= Capaz de assumir e manter a posição de quatro com muita dificuldade. Incapaz de elevar a cabeça e olhar para frente.

2= Capaz de manter a posição de quatro com o dorso estendido e a cabeça elevada (olhando para frente), mas não consegue arrastar para engatinhar para frente.

3= Capaz de manter a posição de quatro, olhar para frente e engatinhar.

4= Mantém o equilíbrio enquanto eleva e estende uma perna.

\section{Levantar-se do chão}

$0=$ Incapaz, mesmo se for permitido usar a cadeira como apoio.

1= Muita dificuldade. Capaz de levantar-se, mas precisa apoiar-se na cadeira (incapaz, se não for permitido apoiar na cadeira)

2= Dificuldade moderada. Capaz de levantar-se sem o apoio da cadeira, mas precisa apoiar uma ou ambas as mãos nas coxas/joelhos ou no chão (Incapaz sem apoiar as mãos)

$3=$ Pouca dificuldade. Não necessita de apoio das mãos nos joelhos, coxas ou no chão, mas mostra alguma dificuldade durante a subida.

$4=$ nenhuma dificuldade

\section{Levantar-se da cadeira}

$0=$ Incapaz de levantar-se da cadeira, mesmo se for permitido apoiar as mãos nas laterais do assento.

1= Muita dificuldade. Capaz, mas necessita apoio das mãos nas laterais do assento.

2= Dificuldade moderada. Capaz, mas apoia as mãos nos joelhos/coxas. Não precisa apoiar nas laterais do assento.

3= Pouca dificuldade. Não necessita de apoio das mãos nas laterais do assento, joelhos ou coxas, mas tem alguma dificuldade durante a subida.

$4=$ nenhuma dificuldade

\section{Subir um degrau no banquinho ou escadinha}

$0=$ Incapaz

1= Muita dificuldade. Capaz, mas necessita de apoiar as mãos na mesa de exame (ou na mão do examinador)

2= Alguma dificuldade. Não necessita apoiar na mesa de exame (ou na mão do examinador) mas apoia as mãos nos seus joelhos/coxa.

3= Capaz. Não necessita apoiar na mesa de exame, ou colocar as mãos nos seus joelhos/coxas.

\section{Apanhar um objeto no chão}

$0=$ incapaz de curvar-se e abaixar para apanhar o objeto no chão.

1= Muita dificuldade. Capaz, mas precisa muito do apoio das mãos nos joelhos/coxas

2= Alguma dificuldade. Tem alguma dificuldade (mas não excessiva). Precisa de um apoio mínimo das mãos sobre os joelhos/coxas, e um pouco lento.

3= Nenhuma dificuldade. Não requer nenhuma manobra compensatória.

\# A pontuação máxima possível para os 14 exercícios (manobras) é de 52. 


\title{
Anexo 5. Teste Manual da Força Muscular (MMT)
}

\author{
MANUAL MUSCLE TESTING (MMT)
}

\author{
INSTRUÇÕES PARA A AVALIACAO DA FORCA MUSCULAR PELA ESCALA DE \\ KENDALL
}

(Com a permissão do "International Myositis Outcome Assessment Collaborative Study Group")

A avaliação da forca muscular utilizando a escala de Kendall modificada da escala original de 0-5 será aplicada para crianças acima de 4 anos. Abaixo da faixa etária de 4-5 anos há limitações para cooperação e entendimento dos comandos para a realização do teste. Sinta-se à vontade para realizar a avaliação de crianças menores que se mostrarem cooperativas com os comandos para as tarefas. A forca muscular proximal e distal será avaliada considerando o grau da amplitude dos movimentos.

[A modificação de Kendall permite desdobrar em (+) e (-) as determinações a partir do grau 2 da escala padrão de 0-5, desta forma convertendo-a para uma 'escala expandida' de 0-10 .] O teste manual de avaliação da força muscular será realizado UNILATERALMENTE (somente do lado direito) para os seguintes grupos musculares: flexores do pescoço, deltóide, bíceps, extensores do punho, gluteus maximus, gluteus medius, quadriceps, dorsiflexores dos tornozelos (Veja as instruções na próxima página).

CÁLCULO DA PONTUAÇÃO FINAL

Número total de músculos (ou grupos musculares) testados

Pontuação final (0-10)

Referência: Legg AT, Merril JB: Physical Therapy in Infantile Paralysis, reprinted from 'Principles ans Paractice of Physical Therapy'. Edited by Mock Pemberton and Coulter, Hagerstown, MD WF Prior Co., Inc. 1932; 45-71.

\begin{tabular}{|c|c|c|}
\hline \multicolumn{3}{|c|}{ PONTUAÇÃO PARA A AVALIAÇÃO DA FORÇA MUSCULAR PELA ESCALA DE KENDALL } \\
\hline & FUNÇÃO DO MÚSCULO & $\begin{array}{l}\text { Escala } \\
\text { de } 0-10\end{array}$ \\
\hline \multirow{2}{*}{$\begin{array}{l}\text { Ausência de } \\
\text { movimento }\end{array}$} & Nenhuma contração (ou fasciculações) palpáveis & \multirow[t]{2}{*}{0} \\
\hline & Tendões tornam-se proeminentes ou tênue contração muscular palpável & \\
\hline \multirow{6}{*}{$\begin{array}{l}\text { Teste de } \\
\text { Movimento }\end{array}$} & MOVIMENTOS NO PLANO HORIZONTAL & \\
\hline & Movimenta-se com amplitude parcial dos movimentos & 1 \\
\hline & Movimenta-se com amplitude total dos movimentos & 2 \\
\hline & $\begin{array}{l}\text { Apresenta amplitude total dos movimentos contra resistência ou } \\
\text { apresenta amplitude dos movimentos total contra a pressão }\end{array}$ & \multirow[t]{3}{*}{3} \\
\hline & POSIÇÃO ANTIGRAVITACIONAL & \\
\hline & Movimentos anti-gravitacionais com amplitude parcial & \\
\hline \multirow{7}{*}{$\begin{array}{l}\text { Teste das } \\
\text { Posições }\end{array}$} & Liberação gradual da posição testada & 4 \\
\hline & Permanece na posição testada (sem nenhuma pressão) & 5 \\
\hline & Permanece na posição testada contra uma pressão leve & 6 \\
\hline & Permanece na posição testada contra uma pressão leve a moderada & 7 \\
\hline & Permanece na posição testada contra uma pressão moderada & 8 \\
\hline & Permanece na posição testada contra uma pressão moderada a intensa & 9 \\
\hline & Permanece na posição testada contra uma pressão intensa & 10 \\
\hline
\end{tabular}

\section{PADRONIZAÇÃO DOS COMANDOS PARA O TESTE DE AVALIAÇÃO DA FORÇA MUSCULAR MANUAL (MMT)}

"QUEREMOS VER SE VOCE ESTÁ FORTE DE VERDADE! Quando eu disser para você segurar e não deixar que eu te empurre, tente segurar com força para não me deixar vencer. Você tem que ser forte como um 'power ranger' (pode ser sugerido qualquer herói nacional ou personagem popular, veja o que cai bem para motivar os seus pacientes).

1- FLEXORES DO PESCOÇO: (Deitado de costas) Levante a sua cabeça acima da mesa e segure. E agora segure firme enquanto eu empurro para baixo, não deixe baixar a cabeça e segure o mais forte que puder. 
2- DELTÓIDE MÉDIO: Segure o seu braço para cima (demonstre), e eu vou empurrar para abaixar o seu braço. Não deixe cair, segure o mais forte que puder.

3- BíCEPS BRAQUIAL: 'Vamos brincar de braço de ferro/ quebra de braço', (flexione o cotovelo para demonstrar). Dobre (flexione) o cotovelo e me impeça de puxar para baixo, segure firme e não me deixe abaixar o seu braço.

4- EXTENSORES DOS PUNHOS: Estenda completamente os punhos mantendo a posição enquanto eu tento puxar a sua mão para baixo, não deixe que eu abaixe a sua mão. Mostre a sua força.

5- GLUTEUS MAXIMUS: Deite de barriga para baixo e dobre os joelhos. Agora tente elevar a perna toda para cima (demonstre passivamente). Segure-a nesta posição, enquanto eu tento empurra-la para baixo. Segure firme e não me deixe empurrar.

6- GLUTEUS MEDIUS: Você pode deitar-se de lado (esquerdo)? Agora voce consegue levantar a perna mantendo os joelhos completamente estendidos? Agora segure firme a perna no ar enquanto eu tento empurrar a sua perna para baixo. Segure firme e com muita força.

7- QUADRICEPS: Sentado com apoio, chute a perna para o alto e a mantenha elevada com os joelhos estendidos. Segure firme nesta posição enquanto eu tento abaixar e dobrar o seu joelho. Seja forte e mantenha a perna estendida no ar.

8- DORSIFLEXORES DOS TORNOZELOS: Dobre (Flexione) o seu pé para cima (demonstre) e segure-o enquanto eu tento empurrá-lo para baixo. Não me deixe empurrá-lo para baixo.

Medida da Força Muscular pelo Método Manual de Kendall em escala de 0-10 (MMT 0-10)

\begin{tabular}{|c|c|c|c|c|c|c|c|c|c|c|c|}
\hline \multirow[t]{2}{*}{ Avaliação conjunta de 8 grupos musculares } & \multicolumn{11}{|c|}{ Avaliar apenas o lado direito } \\
\hline & 0 & 1 & 2 & 3 & 4 & 5 & 6 & 7 & 8 & 9 & 10 \\
\hline \multicolumn{12}{|l|}{ 1- Flexores do Pescoço } \\
\hline \multicolumn{12}{|l|}{ 2- Deltóide médio (abdução do ombro) } \\
\hline \multicolumn{12}{|l|}{ 3- Bíceps Braquial (flexão do antebraço) } \\
\hline \multicolumn{12}{|l|}{ 4- Extensão do Punho } \\
\hline \multicolumn{12}{|l|}{ 5- Gluteus Maximus (extensão do quadril) } \\
\hline \multicolumn{12}{|l|}{ 6- Gluteus Medius (abdução do quadril) } \\
\hline \multicolumn{12}{|l|}{ 7- Quadríceps (flexão do quadril) } \\
\hline 8- Dorsiflexão dos Tornozelos & & & & & & & & & & & \\
\hline
\end{tabular}




\section{Anexo 6. Estadio Puberal de Tanner}

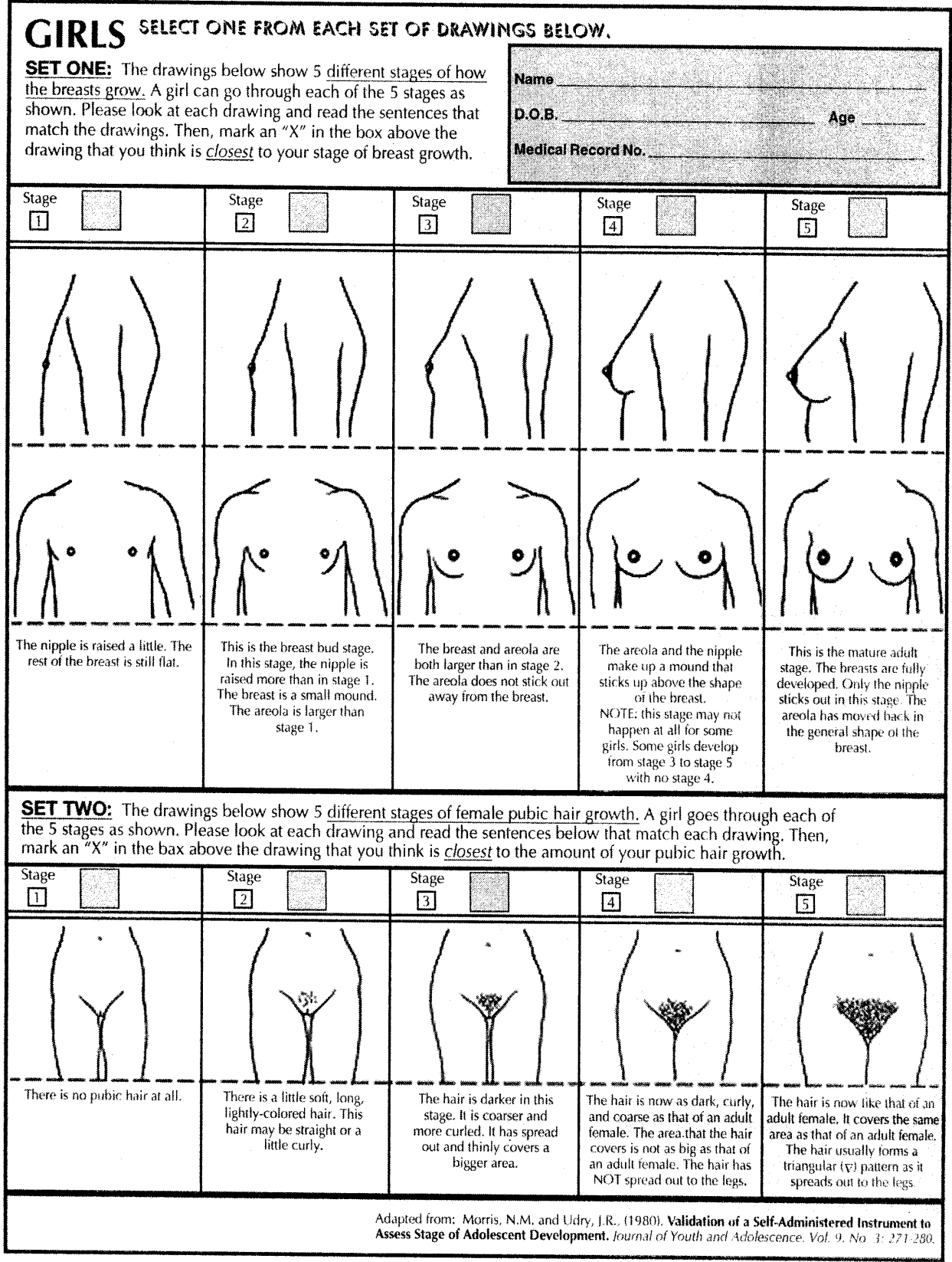

Fig. 5. Self administered pubertal assessment form: girls. Adapted from Morris NM and Udry IR J Youth Adol 1980;9(3);271-280. 
Alsufyani KA, Ortiz-Alvarez $O$, Cabral DA, et al. Bone mineral density in children and adolescents with systemic lupus erythematosus, juvenile dermatomyositis and systemic vasculitis: relationship to disease duration, cumulative corticosteroid dose, calcium intake and exercise. J Rheumatol 2005;32:729-33.

Bachrach LK, Hastie T, Wang MC, Narasimhan B, Marcus R. Bone mineral acquisition in heathy Asian, Hispanic, Black, and Caucasian youth: A longitudinal study. J Clin Endocrinol Metab 1999;84:4702-4712.

Bezerra MC, Calomeni GD, Caparbo VF, Gebrim ES, Rocha MS, Pereira RMR. Low bone density and low serum levels of soluble RANK ligand are associated with severe arterial calcification in patients with Takayasu arteritis. Rheumatology 2005;44:1503-06 (a).

Bezerra MC, Carvalho JF, Prokopowitsch AS, Pereira RMR. RANK, RANKL and osteoprotegerina in arthritis bone loss. Braz J Med Biol Res 2005; 38:161-70 (b).

Bode RK, Klein-Gitelman MS, Miller ML, Lechman TS, Pachman LM. Disease activity score for children with juvenile dermatomyositis: reliability and validity evidence. Arthritis Rheum 2003;49:7-15.

Bohan A, Peter JB. Polymyositis and dermatomyositis. N Engl J Med 1975; 292:344-7. 
Bonjour J P, Theintz G, Buchs B, Slosman D \& Rizzoli R. Critical years an stages of puberty for spinal and femoral bone mass accumulation during adolescence. J Clin Endocrinol Metab 1991;73:555-63.

Brambilla $\mathrm{P}$, Rolland-Cachera $\mathrm{M}-\mathrm{F}$, Testolin $\mathrm{C}$ et al. Lean mass of children in various nutritional states. Comparison between dual-energy X-ray absorptiometry and anthropometry. Ann N Y Acad Sci 2000;904:433-6.

Carter DR, Bouxsein ML, Marcus R. New approaches for interpreting projected bone densitometry data. J Bone Miner Res 1992;7:137-145.

Cassidy JT. Osteopenia and osteoporosis in children. Clin Exp Rheumatol $1999 ; 17: 245-2550$.

Castro TCM, Terreri MTRA, Szejnfeld VL, Len C, Fonseca ASM, Hilário MOE. Bone mineral density of Brazilian girls with juvenile dermatomyositis. Braz J Med Biol Res 2005;38:309-13.

Crabtree NJ, Leonard MB, Zemel BS. Dual-Energy X-Ray Absorptiometry. In Sawyer AJ, Bachrach LK, Fung EB, eds. Bone Densitometry in Growing Patients: Guidelines for Clinical Practice. Totowa, New Jersey: Humana Press Inc, 2007;41-57.

Cvijetic S, Korsic M. Apparent bone mineral density estimated from DXA in healthy men and women. Osteoporos int 2004;15:295-300.

Falcini F, Trapani S, Civinini R, Capone A, Ermini M, Bartolozzi G. The primary role of steroids on the osteoporosis in juvenile rheumatoid patients evaluated by dual energy X-ray absorptiometry. J Endocrinol Invest 1996;19:165-9. 
Florence JM, Pandya S, King WM et al. Intrarater reliability of manual muscle test (Medical Research Council scale) grades in Duchenne's muscular dystrophy. Phys Ther 1992;72:115-22.

Genant HK, Engelke K, Fuerst T, et al. Noninvasive Assessment of bone mineral and structure:state of the art. J Bone Miner Res 1996;11:707-30.

Hansen M, Halberg P, Kollerup $G$ et al. Bone metabolism in patients in patients with systemic lupus erythematosus. Effect of disease activity and glucocorticoid treatment. Scand J Rheumatol 1998;27:197-206.

Haugeberg G, Griffiths B, Sokoll KB, Emery P. Bone loss in patients treated with pulses of methylprednisolone is not negligible: a short term prospective observational study. Ann Rheum Dis 2004;63:940-4.

Haugen M, Lien G, Flato B, et al. Young adults with juvenile arthritis in remission attain normal peak bone mass at lumbar spine and forearm. Arthritis Rheum 2000;43:1504-10.

Hofbauer LC, Schoppet M. Clinical implications of osteoprotegerin/ RANKL/RANK system for bone and vascular diseases. JAMA 2004:292:490-5

Johnston CC Jr, Miller JZ, Slemenda CW, et al. Calcium suplementation and increases in bone mineral density in children. N Engl J Med 1992;327:82-7.

Khan AA, Bachrach L, Brown JP, et al. Standards and guidelines for performing central dual-energy X-ray absorptiometry in premenopausal women, men, and children. J Clin Densitom 2004;51-63. 
Kipen Y, Buchbinder R, Forbes A, Strauss B, Littlejohn G, Morand E. Prevalence of reduced bone mineral density in systemic lupus erythematosus and the role of steroids. J Rheumatol 1997;24:1922-9.

Kipen Y, Strauss JG, Morand EF. Body composition in systemic lupus erythematosus. Br J Rheumatol 1998;37:514-19.

Kong YY, Boyle WJ, Penninger JM. Osteoprotegerin ligand: a regulator of immune responses and bone physiology. Immunol Today 2000;21:495-502.

Kotaniemi A, Savolainen A, Kröger $H$, Kautiainen $H$, Isomaki $H$. Weightbearing physical activity, calcium intake, systemic glucocorticoid, chronic inflammation and body constitution as determinants of lumbar and femoral bone mineral in juvenile chronic arthritis. Scandinavian J Of Rheumatol $1999 ; 28: 19-26$.

Lien G, Selvaag AM, Flato B et al. A two-year prospective controlled study of bone mass and bone turnover in children with early juvenile idiopathic arthritis. Arthritis Rheum 2005;52:883-40.

Lim S, Joung $H$, Shin CS, et al. Body composition changes with age have gender-specific impacts on bone mineral density. Bone 2004;35:792-8.

Lovell DJ, Lindslev CB, Rennebohm RM, et al. Development of validated disease activity and damage indices for the juvenile idiopathic inflammatory myopathies. II. The Childhood Myositis Assessment Scale (CMAS): a quantitative tool for the evaluation of muscle function. The Juvenile Dermatomyositis Disease Activity Collaborative Study Group. Arthritis Rheum 1999;42:2213-9. 
Mackiewicz Z, Hukkanen M, Povilenaite D, et al. Dual effects of caspase-1, interleukin-1 beta, tumour necrosis factor-alpha and nerve growth factor receptor in inflammatory myopathies. Clin Exp Rheumatol 2003;21:41-8.

Mul D, Suijlekom-Smit van LWA, Cate ten R, Bekkering WP, Muinck keizerSchrama de SM. Bone mineral density and body composition and influencing factors in children with rheumatic diseases treated with corticosteroids. J Pediat Endocrinol Metab 2002;15:187-92.

Pepmueller PH, Cassidy JT, Allen SH, Hillman LS. Bone mineralization and bone mineral metabolism in children with juvenile rheumatoid arthritis. Arthritis Rheum 1996;39:746-57.

Pereira RMR, Corrente JE, Chahade W, Yoshinari NH. Evaluation by dual Xray absorptiometry (DXA) of bone mineral density in children with juvenile chronic arthritis. Clin Exp Rheumatol 1998;16:495-501.

Perez MD, Abrams SA, Koenning G, Stuff JE, O`Brien KO, Ellis KJ. Mineral metabolism in children with dermatomyositis. J Rheumatol 1994;21:2364-9.

Rebuffe-Scrive M, Krotkiewski M, Elfverson J, Bjorntorp P. Muscle and adipose tissue morphology and metabolism in Cushing's syndrome. J Clin Endocrinol Metab 1998;67:1122-28.

Reed A, Haugen M, Pachman LM, Langman CB. 25-hydroxyvitamin D therapy in children with active juvenile rheumatoid arthritis: short-term effects on serum effects on serum osteocalcin levels and bone mineral density. J Pediatr 1991;119:657-60. 
Reid IR. Relationships among body mass, its components, and bone. Bone 2002;31:547-55.

Salomonsson S, Lundberg IE. Cytokines in idiopathic inflammatory myopathies. Autoimmunity 2006;39:117-90.

Stewart WA, Acott PD, Salisbury SR, Lang BA. Bone Mineral Density in Juvenile Dermatomyositis. Arthritis Rheum 2003;48:2294-98.

Tanner JM. Growth at adolescence. 2nd ed. Oxford: Blackwell Scientific Publications; 1962.

Taylor A, Konrad PT, Norman ME, Harcke HT. Total body bone mineral density in young children: influence of head bone mineral density. J Bone Miner Res 1997;12:652-5.

Theintz G, Buchs B, Rizzoli R, et al. Longituinal monitoring of bone mass accumulation in healthy adolescents: evidence for a marked reduction after 16 years of age at the levels of lumbar spine and femoral neck in female subjects. J Clin Endocrinol Metab 1992;75:1060-65.

Wang MC, Aguirre M, Bhudhikanok GS, et al. Bone mass and hip axis length in healthy Asian, black, Hispanic, and white American youths. J Bone Miner Res 1997;12:1922-1935.

Warady BD, Lindsley CB, Robinson FG, Lukert BP. Effects of nutritional supplementation on bone mineral status of children with rheumatic diseases receiving corticosteroid therapy. J Rheumatol 1994;21:530-5. 